\title{
Effects of Power Tracking Algorithms on Lifetime of Power Electronic Devices Used in Solar Systems
}

\author{
Canras Batunlu ${ }^{1}$, Mohamad Alrweq ${ }^{2}$ and Alhussein Albarbar ${ }^{2,3, *}$ \\ 1 Department of Electrical and Electronics Engineering, Middle East Technical University, \\ Northern Cyprus Campus, 99738 Kalkanli, Guzelyurt, Mersin 10, Turkey; cbatunlu@metu.edu.tr \\ 2 Advanced Industrial Diagnostics Research Centre, School of Engineering, \\ Manchester Metropolitan University, Manchester M1 5GD, UK; m.alrweq@mmu.ac.uk \\ 3 Faculty of Marine Studies, King Abdulaziz University, Jeddah 21589, Saudi Arabia \\ * Correspondence: a.albarbar@mmu.ac.uk; Tel.: +44-161-274-6297
}

Academic Editor: Senthilarasu Sundaram

Received: 31 August 2016; Accepted: 19 October 2016; Published: 29 October 2016

\begin{abstract}
In photovoltaic solar energy systems, power management algorithms (PMAs), usually called maximum power point tracking (MPPT) algorithms, are widely used for extracting maximum available power at every point in time. However, tracking the maximum power has negative effects on the availability of solar energy systems. This is due, mainly, to the created disturbances and thermal stresses on the associated power electronic converters (PECs). This work investigates the effects of PMA on the lifetime consumption, thermal stresses and failures on DC-DC converters used in solar systems. Firstly theoretical analysis and modelling of photovoltaic solar systems including converter's electro thermal characteristics were developed. Subsequently, experiments on photovoltaic solar systems were carried out using two different PMAs, namely, perturb and observe $(\mathrm{P} \& \mathrm{O})$ and incremental conductance (IC). Real-time data was collected, under different operating conditions, including thermal behavior using thermal imaging camera and dSPACE. Converters' thermal cycling was found to be approximately $3^{\circ} \mathrm{C}$ higher with the IC algorithm. The steady state temperature was $52.7^{\circ} \mathrm{C}$, for the IC while it was $42.6^{\circ} \mathrm{C}$ for P\&O. Although IC algorithm offers more accurate power management tool, it causes more severe thermal stresses which, in this study, has led to approximately 1.4 times greater life consumption compared to $\mathrm{P} \& \mathrm{O}$.
\end{abstract}

Keywords: availability of photovoltaic solar systems; thermal stress of boost converters; power management algorithms (PMAs)

\section{Introduction}

Generating electricity using photovoltaic (PV) solar energy modules is getting more popular due to recent advances in PV-cells and power condition circuitries. The ratio between produced power from the PV systems and their cost is also declining as a result of those technological developments. Power electronic converters (PECs), e.g., DC/DC and DC/AC inverters, are widely used in solar PV applications. However, PV solar systems face a number of failures, which cause concerns related to their reliability and availability, and have negative effects on customers' satisfaction. Alam et al. [1] listed ground faults, line-to-line faults, hot spot formation, polarity mismatch, bypass diode failures, and dust/soil formation, as the major failures in PV systems. DeGraaff et al. [2] presented failure distribution in a PV system, over a period of 8 years. They found the highest failure rate (36\%) comes from the internal electrical circuit, which includes the power electronic components, followed by junction box and cables (12\%), burn marks on cells $(10 \%)$, and encapsulated failure $(9 \%)$ as shown in Figure 1a. Among possible failure causes of PECs in PV installations and maintenance stated by Tsoutsos et al. [3] are wrong positioning, where they are directly exposed to the sunlight which causes 
temperature fluctuations, insufficient ventilation, placement at a long distance from the PV array combiner/junction box, and installation on or near a combustible surface. A similar study proposed by Moore and Post [4] also stated that PEC components are responsible of $37 \%$ of unscheduled maintenance which is $10 \%$ higher than the combined total of the junction box $(12 \%)$ and PV panel itself $(15 \%)$, as shown in Figure 1b [4].

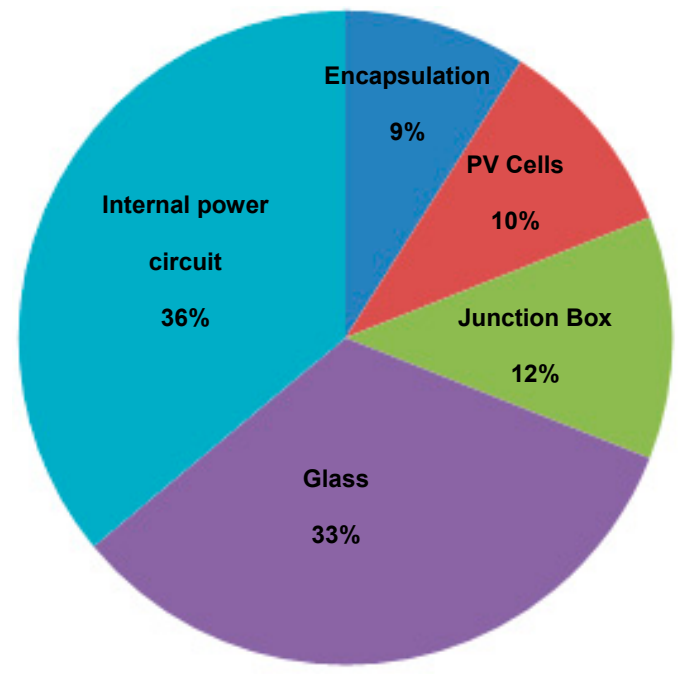

(a)

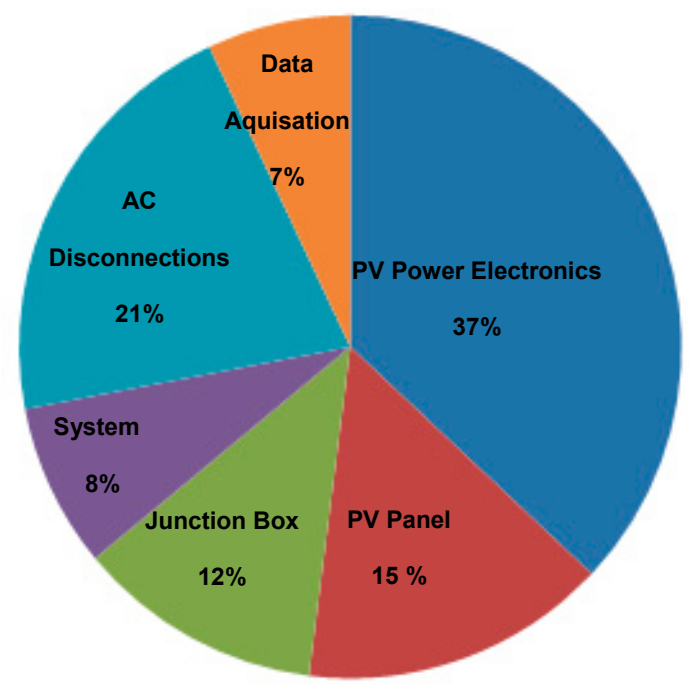

(b)

Figure 1. Failures in photovoltaic (PV) systems: (a) failure distribution [2]; and (b) unscheduled maintenance events [4].

Hence, about $\sim 40 \%$ of failures in PV solar systems are caused by power electronic devices and thus rigorous analysis on the PECs lifetime is timely needed. Physics of failure approach is one method that deals with the impact of materials, defects and stress on power electronic devices [5].

PECs governed by mathematical algorithms are embedded in solar energy applications to ensure extracting the available maximum power under different operating condition as shown in Figure 2. Those algorithms are known as power management algorithms (PMAs) or maximum power point tracking (MPPT) algorithms that are established via a number of methodological approaches.

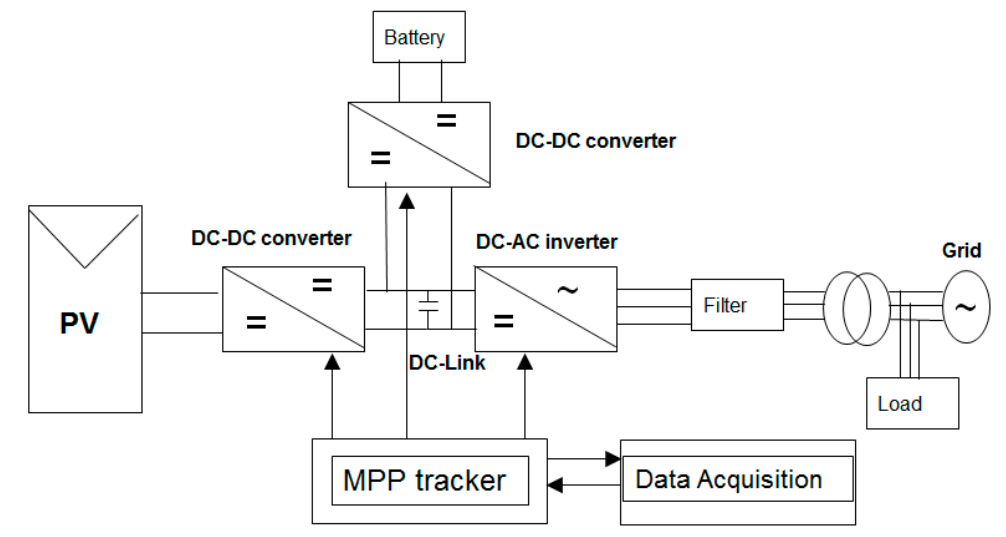

Figure 2. PV system connection to grid and load via DC-DC and DC-AC conversion.

Perturb and observe (P\&O) [6] and incremental conductance (IC) [7] are the most popular PMAs used. A large amount of research work has been devoted to improving the efficiency, tracking speed and accuracy of those algorithms. Zhang et al. [8] developed the MPPT method which uses a sliding mode strategy by controlling duty cycle of a buck converter and improved efficiency by $5 \%$. 
Liu et al. [9] compared the conventional P\&O method with an improved version and 93\% efficiency was achieved while for the conventional one this value was $72 \%$. Houssamo et al. [10] presented experimental comparison between $\mathrm{P} \& \mathrm{O}$ and IC algorithms for maximizing the output power from a $\mathrm{PV}$. Algorithms were also compared in terms of voltage ripples, dynamic responses and experimental tracking factor (TF) [11,12]. Azevedo et al. [13] studied the effects of the improvements on both algorithms such as adjustment of the sampling rate, perturbation size, etc. Ishaque et al. [14] stated that the IC method is slightly better since it gives $98.5 \%$ MPPT efficiency compared to $98.3 \%$ of $\mathrm{P} \& \mathrm{O}$, based on a study conducted on a MPPT converter attached to a PV array simulator. It was also observed that the performance of IC is highly dependent on its step size, especially at low insolation levels. Dash et al. [15] proposed that although the $\mathrm{P} \& \mathrm{O}$ algorithm is easier to implement, IC is more accurate under rapidly changing irradiance conditions. The DSP controller feature of the dSPACE real time interface (RTI) system is widely used in the literature for implementing MPPT algorithms and to provide duty cycle control signal for PECs employed within PV systems. For instance, Mahdi et al. [16] implemented an improved $\mathrm{P} \& \mathrm{O}$ algorithm to ensure optimal operating points of a PV system using a dSPACE DSP controller. Mathematical equations which describe the nonlinear characteristics of a PV panel to design a MPPT can also be implemented by using dSPACE as presented in [17]. Graditi et al. [18,19] presented energy performances and reliability evaluation of converters [20]. A longer lifetime inverter for PV AC modules was also studied in [21]. However, in the literature, to the best knowledge of the authors of this article, no comparative study has been presented about the electro-thermal effects of the MPPT algorithms on the DC/DC converters employed within PV systems, although the temperature influence and importance of the electro-thermal design were mentioned in $[22,23]$ and an improved thermal profile for PV inverters was assessed by power limit control method within the P\&O method in $[24,25]$. Most of the studies focused on comparing the tracking efficiency, signal ripple, speed response, sensitivity to environmental conditions, and ease of hardware and software implementation and converter suitability among MPPT methods. However, the lifetime of the DC/DC converter which operates the MPPT has a vital effect on the reliability of solar PV applications. The operating principles of each MPPT algorithm also differ from each other. This produces different power loss profiles which cause dissimilar operating temperature amplitude and fluctuations for PECs. Therefore, it is essential to explore the operational difference characteristics for reliability assessment among MPPT algorithms.

This work investigates the effects of IC and P\&O PMAs on the thermal stresses and reliability of PEC modules. It starts by implementing PV model, the associated MPPT algorithms and a realistic electro-thermal model of a power electronic module's switching component (insulated gate bipolar transistor, IGBT) in Section 2. Experimental setup and DC-DC boost converter real time temperature monitoring interfaced with dSPACE are demonstrated in Section 3. Section 4 presents the electro-thermal performance and reliability comparison of PECs under the IC and P\&O algorithms. Power electronics modules lifetime analysis and effects under both algorithms are discussed in Section 5. A broad discussion on the simulated and experimental results was presented in Section 6 and Conclusions are summarized in the final section.

In order to extend existing studies in literature, an electro-thermal model of the PEC was implemented. Temperature variations of IGBT were determined when IC and P\&O algorithms were applied as MPPT method and these profiles were used in reliability models for lifetime consumption estimation.

\section{Photovoltaic Solar System Modelling and Characteristic}

The PV solar cell internal photocurrent, $I_{P H}$, within PV cell equivalent circuit is shown in Figure 3 along with the boost converter for MPPT application purposes. 


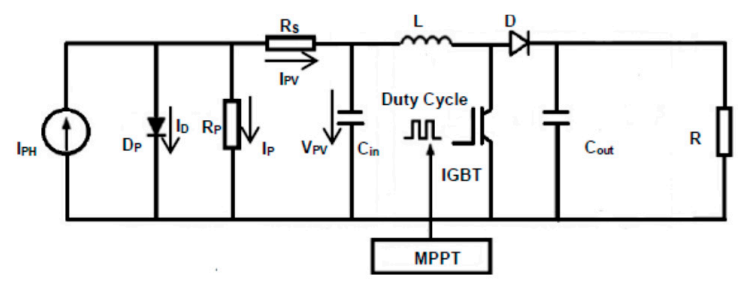

Figure 3. PV solar cell equivalent circuit integrated within a maximum power point tracking (MPPT) system.

A parallel diode, $D_{P}$, internal series and parallel resistances $\left(R_{S}\right.$ and $\left.R_{P}\right)$ can also be seen in this circuit along with total current and voltage $I_{P V}$ and $V_{P V}$, respectively. Total current, $I_{P V}$, can be represented with respect to diode, $I_{D}$ and parallel resistance currents, $I_{P}$ as in Equations (1) and (2):

$$
\begin{gathered}
I_{P V}=I_{P H}-I_{D}-I_{P} \\
I_{P V}=I_{P H}-I_{0}\left(\exp \left[\frac{q\left(V_{P V}+I_{P V} R_{S}\right)}{A k T_{C}}\right]-1\right)-\frac{V_{P V}+I_{P V} R_{S}}{R_{P}}
\end{gathered}
$$

where $I_{0}$ is the total diffusion current, $V_{P V}$ is the output voltage, $q$ is the charge of one electron, $T_{\mathcal{C}}$ is the solar cell temperature, $k$ is the Boltzmann constant and $A$ is junction perfection factor which determines the diode deviation from the ideal p-n junction. For deriving the numerical model of a PV module, Equation (2) can be rearranged to Equation (3):

$$
I_{P V}\left(1+\frac{R_{s T}}{R_{s h T}}\right)=n_{p} I_{P H}-n_{p} I_{0}\left(\exp \left[\frac{q\left(\frac{V_{P V}}{n_{s}}+I_{P V} R_{s T}\right)}{A k T_{c}}\right]-1\right)-\frac{V_{P V} / n_{s}}{R_{s h T}}
$$

where for $n_{p}$ cells in parallel and $n_{s}$ cells in series the $R_{s h T}=\frac{n_{p}}{n_{s}} \times R_{p}$ and $R_{s T}=\frac{n_{s}}{n_{p}} \times R_{s}$. Compared to the $R_{s}$, the value of $R_{p}$ has little impact on the output characteristics of PV cells. Hence, by neglecting the $R_{p}, \mathrm{PV}$ voltage, $V_{P V}$, is represented as a function of the current, $I_{P V}$ [12], as:

$$
V_{P V}=2 n\left(k T_{c} / q\right) n_{s} \ln \left(\frac{n_{p} I_{g}-I_{P V}}{n_{p} I_{0}}+1\right)-\frac{2 n_{s} R_{s}}{n_{p}} I_{P V}
$$

\begin{tabular}{|c|c|c|c|c|c|}
\hline $\begin{array}{l}\text { Electrical Performance } \\
\left(\text { at } 1 \mathrm{~kW} / \mathrm{m}^{2}\right)\end{array}$ & $\begin{array}{l}\text { Maximum } \\
\text { Power }\end{array}$ & $\begin{array}{c}\text { Maximum } \\
\text { Voltage }\end{array}$ & $\begin{array}{c}\text { Maximum } \\
\text { Current }\end{array}$ & $\begin{array}{l}\text { Open Circuit } \\
\text { Voltage }\left(V_{\text {oc }}\right)\end{array}$ & $\begin{array}{l}\text { Short Circuit } \\
\text { Current }\left(I_{\mathrm{sc}}\right)\end{array}$ \\
\hline Values & $54 \mathrm{~W}$ & $17.4 \mathrm{~V}$ & $3.11 \mathrm{~A}$ & $21.7 \mathrm{~V}$ & $3.31 \mathrm{~A}$ \\
\hline Physical Properties & $n_{s}$ & $n_{p}$ & $R_{S}$ & $R_{p}$ & - \\
\hline Values & 36 & 1 & 0.691 & 10,850 & - \\
\hline
\end{tabular}

The characteristic of the PV module used in this work is listed in Table $1[26,27]$. Based on Equations (1)-(4), electrical model of this component was implemented by using MATLAB/Simulink.

Table 1. Photovoltaic module parameter specifications [26,27].

\subsection{Power Management Algorithms}

$\mathrm{P} \& \mathrm{O}$ and IC algorithms were implemented for MPPT purposes in MATLAB/Simulink. The maximum power point, expression, $P_{P V, m p p}$, can be described in Equation (5):

$$
P_{P V, m p p}=I_{P V, m p p} . V_{P V, m p p}=\left(I_{P H}-I_{0}\left[\exp \left(q V_{P V, m p p} / A k T_{c}\right)-1\right]\right) V_{P V, m p p}
$$

\subsubsection{Incremental Conductance Maximum Power Point Tracking Algorithm}

IC MPPT method is based on the derivative of the power with respect to the voltage at $P-V$ curve which is equivalent to zero at the maximum power point. Hence, by comparing the instantaneous 
conductance $\left(I_{p v} / V_{p v}\right)$ with incremental one $\left(\Delta I_{p v} / \Delta V_{p v}\right)$ the maximum power point is tracked based on the sign of the $\Delta P_{p v} / \Delta V_{p v}$ and varying the operating voltage. A flowchart of IC methods can be seen in Figure 4a.

$$
\frac{d P_{p v}}{d V_{p v}}=\frac{d\left(V_{p v} I_{p v}\right)}{d V_{p v}}=I_{p v} \frac{d V_{p v}}{d V_{p v}}+V_{p v} \frac{d I_{p v}}{d V_{p v}}=I_{p v}+V_{p v} \frac{d I_{p v}}{d V_{p v}} \cong I_{p v}+V_{p v} \frac{\Delta I_{p v}}{\Delta V_{p v}}
$$

The maximum power point of solar PV module can be defined as:

$$
\frac{d P_{p v}}{d V_{p v}}=0 \Rightarrow I_{p v}+V_{p v} \frac{d I_{p v}}{d V_{p v}}=0 \Rightarrow-\frac{I_{p v}}{V_{p v}}=\frac{d I_{p v}}{d V_{p v}}
$$

From Equation (7), operating points of the PV module with respect to IC algorithm can be written as:

$$
\frac{d P_{p v}}{d V_{p v}}=0, \text { for } V_{p v}=V_{p v, m p p} \text { and } \Delta I_{p v} / \Delta V_{p v}=-I_{p v} / V_{p v}
$$

where the module is operated at MPP and the $V_{p v}$ should be held as it is:

$$
\frac{d P_{p v}}{d V_{p v}}>0, \text { for } V_{p v}<V_{p v, m p p} \text { and } \Delta I_{p v} / \Delta V_{p v}>-I_{p v} / V_{p v}
$$

where the $V_{p v}$ should be increased by applying constant steps to reach $V_{p v, m p p}$ :

$$
\frac{d P_{p v}}{d V_{p v}}<0, \text { for } V_{p v}>V_{p v, m p p} \text { and } \Delta I_{p v} / \Delta V_{p v}<-I_{p v} / V_{p v}
$$

where the $V_{p v}$ should be controlled by applying constant steps to be reduced until $V_{p v, m p p}$.

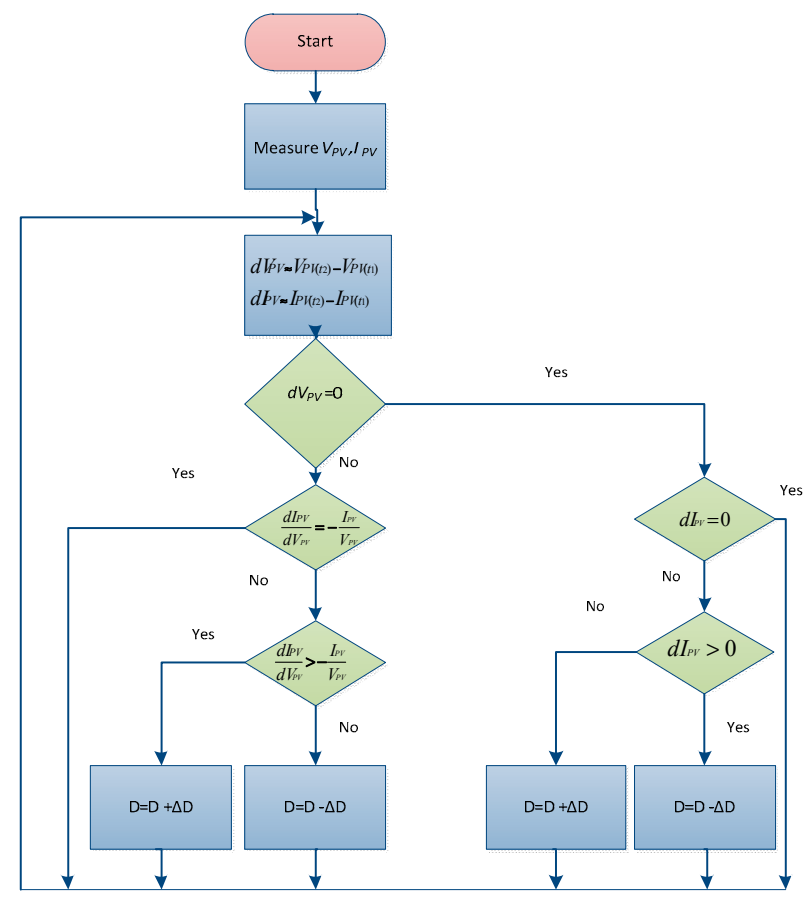

(a)

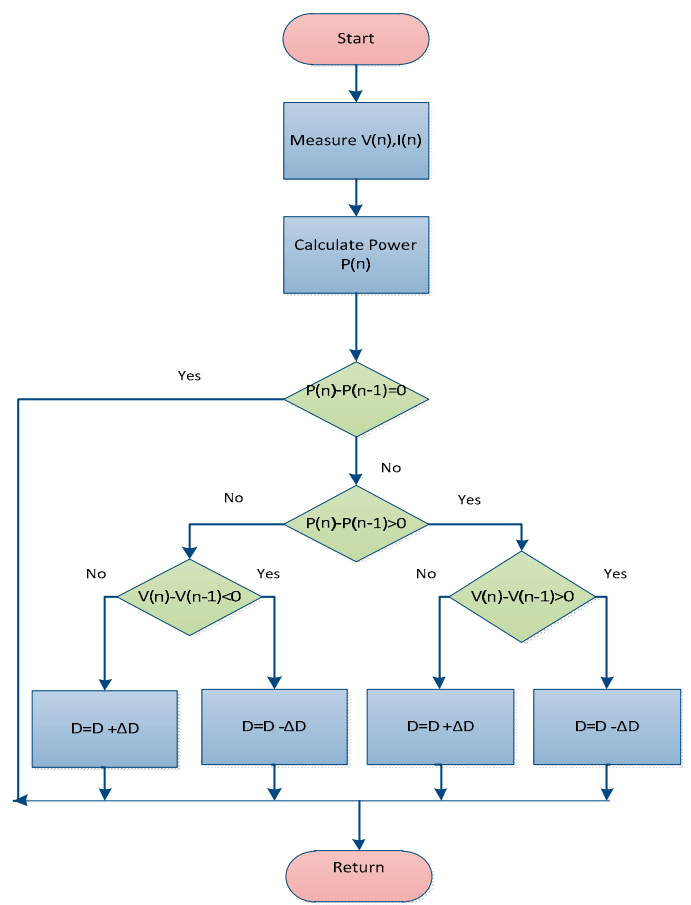

(b)

Figure 4. Flowchart of (a) incremental conductance (IC) and (b) perturb and observe (P\&O) Methods. 


\subsubsection{Perturb \& Observe Maximum Power Point Tracking Algorithm}

The perturb \& observe (P\&O) MPPT algorithm is derived by producing disturbances to either instantaneous current or voltage which was used as a reference in this study. By changing the solar panel voltage in a small amouns, the system $I-V$ operating point and hence $P-V$ characteristics are changed. However, changes in the amount of power can either be positive or negative. In the case that it is positive disturbance should follow the same direction until the MPP is approached. Otherwise, perturbation direction should be changed to prevent moving further away from MPP. The step size of the disturbance can be decreased when it is closer to MPP to avoid large oscillations. A flowchart of the $\mathrm{P} \& \mathrm{O}$ method can be seen in Figure $4 \mathrm{~b}$.

\subsection{Maximum Power Point Tracking Tracking Efficiency}

The MPPT tracking efficiency $\left(e f f_{M P P T}\right)$ is the ratio between the extracted and available power during each operating condition sequence. It can be derived into Equation (11):

$$
e f f_{M P P T}=\frac{\int_{0}^{T} V_{p v}(t) \times I_{p v}(t) d t}{\int_{0}^{T} P_{P V m p p}(t) d t}
$$

where $V_{P V}(t)$ and $I_{P V}(t)$ are the instantaneous PV voltage and current, $P_{P V m p p}(t)$ is the available maximum power and $T$ is the period of the experimental data.

The efficiency of the MPPT was obtained for both the P\&O and IC account simultaneously in order to evaluate its effects on the thermal profiles of the switching devices and to provide a detailed comparison.

\subsection{Electro Thermal Model of Boost Converter within Maximum Power Point Tracking}

Boost DC/DC converter was used for matching the MPP of the PV module at any irradiance and temperature level along with an MPPT control, PWM block and a load. Operating point of the PV module is changed by the duty cycle of the switching element (IGBT) according to MPPT algorithms to reach the single value of maximum power point duty cycle, $D_{M P P}$. Operating of boost converter occurs in ON and OFF stages in period of $T$. During the ON stage, for DT seconds, the IGBT is closed which results in an increase of the inductor current. The current flow through the IGBT generate conduction losses when the device is in full conduction. These losses are also in direct relationship with the duty cycle. Thermal cycling on this component results in deformation and eventual failures, which account for around $60 \%$ of overall PEC runaways. Therefore, only an electro-thermal model of this device was implemented. During OFF stage, the accumulated energy transfers into the capacitor and load resistance through the flyback diode. At this stage, no heat losses occur. For both stages, circuit equivalences of the converter, when coupled with PV module, can be written as:

$$
\frac{V_{P V}}{L} D T=-\frac{V_{P V}-V_{O U T}}{L}(1-D) T
$$

Equation (12) can be simplified to derive the relationship between input/output voltage as:

$$
\frac{V_{P V}}{V_{\text {OUT }}}=1-D
$$

Two types of energy losses occur during operation of IGBT; first, switching energy losses, $E_{S W}$, occur, over one period of switching processes due to drastic change in current / voltage across the device when the device is transitioning from the blocking state to the conducting state and vice-versa. They are divided into Turn-On and Turn-Off losses, $E_{O N}$ and $E_{O F F}$, for the IGBT. They can be expressed 
as a function of collector current $I_{C E}$, collector-emitter saturation voltage $V_{C E}$ and junction temperature $T_{J}$ as shown in Equation (14):

$$
E_{S W}=\int_{\text {turn-on }} E_{O N} \cdot(t) d t+\int_{t u r n-o f f} E_{O F F}(t) \cdot d t=f\left(V_{C E}, I_{C E}, T_{J}\right)
$$

Hence, the switching power losses, $P_{S W}$, are:

$$
P_{S W}=\left(E_{S W}\right) f_{s w}
$$

where $f_{s w}$ is the switching frequency. Second, conduction power loss, $P_{\mathrm{CON}}$, for a single device is:

$$
P_{C O N}=V_{C E} \cdot I_{C E}=f\left(I_{C E}, T_{J}, D\right)
$$

\section{Experimental Setup}

A boost converter was constructed with specified component ratings listed in Table 2, namely with an iron-core type inductor, a fast recovery diode and two input and output capacitors.

Table 2. Boost converter parameter specifications. IGBT: insulated gate bipolar transistor.

\begin{tabular}{cccc}
\hline Switching Elements & IGBTs & Diode & Switching Frequency \\
\hline Ratings & $600 \mathrm{~V} / 15 \mathrm{~A}$ & $300 \mathrm{~V} / 20 \mathrm{~A}$ & $20 \mathrm{kHz}$ \\
\hline Storing and Load Elements & Resistor $(\boldsymbol{R})$ & Inductor $(L)$ & Capacitors $\left(\boldsymbol{C}_{\text {in }}, \boldsymbol{C}_{\text {out }}\right)$ \\
\hline Ratings & $100 \Omega$ & $1 \mathrm{mH}, 250 \mathrm{~V}, 12 \mathrm{~A}$ & $82 \mu \mathrm{F}, 450 \mathrm{~V}$ \\
\hline
\end{tabular}

MPPT algorithms were individually implemented using Simulink and integrated with dSPACE through the control desk. Gate signals generated through MPPT blocks were provided through a DS5101 digital to analogue converter card. Due to gate requirements, gate drivers were used to reach sufficient power level. In order to isolate low power switching signal from dSPACE board and high power converter circuit, a driver circuit has been designed using HP403 opt coupler. Then the isolated gate signal is inverted by a TD351 IGBT driver in the driving circuit. This is also required in order to provide the driving signal with sufficient current and voltage level $(\approx 15 \mathrm{~V})$ to appropriately turn on and turn off the IGBT. Collector current, $I_{c e}$, and PV current, $I_{P V}$, were monitored by current transducers, LA 25-NP, and were inserted dSPACE RTI through DS2004ADC as power loss and MPPT algorithm model inputs. PV and collector to emitter voltages, $V_{P V}$ and $V_{c e}$ were also measured for operating within same blocks as current signals. The schematic diagram of the experimental set up is shown in Figure 5a and the Simulink model of the boost converter embedded with the PV model is presented in Figure 5b.

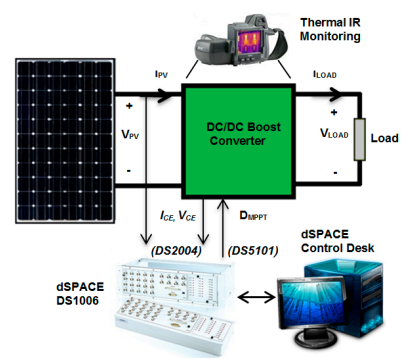

(a)

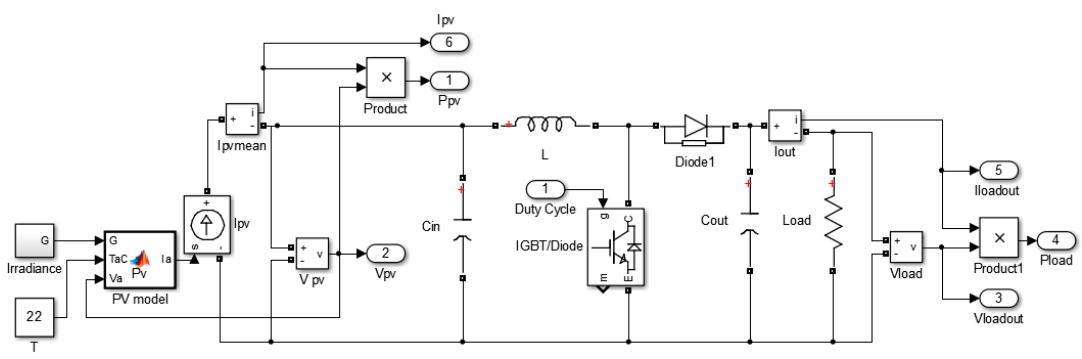

(b)

Figure 5. Schematic diagram of (a) experimental set-up, and (b) boost converter model in Simulink. 
Implemented IC and P\&O algorithms within Simulink and dSPACE are shown in Figure 6. The MPPT could have been implemented by sensing the PV current and voltage to calculate the instantaneous power. Then, by comparing it with the available power, the duty cycle of the converter could be adjusted using PI controllers, multiple loops or hysteresis controllers. However, different MPPT algorithms could require different tuning parameters for a specific controller type; hence, a fair comparison between $\mathrm{P} \& \mathrm{O}$ and IC algorithms themselves would not be established in terms their effect on the lifetime consumption of the converters. Therefore, the control method was directly computed in the MPPT algorithms to update the duty cycle of the converters. This method is also known as the direct duty cycle MPPT. It is also advantageous since it eliminates the controller tuning and decreases the computation time efforts [18]. The perturbation step size has significant effect on the energy efficiency especially under dynamic weather conditions. As the perturbation step size gets larger, the efficiency improves but it causes oscillations around MPP and during low irradiance level changes. Inversely, the low perturbation step size decreases the oscillations but provides low efficiencies during high irradiance level changes. In other words, this parameter plays a key role for balancing efficiency and the fluctuations around MPP. In this work, it was selected as 0.005 for both methods as a result of several tests.

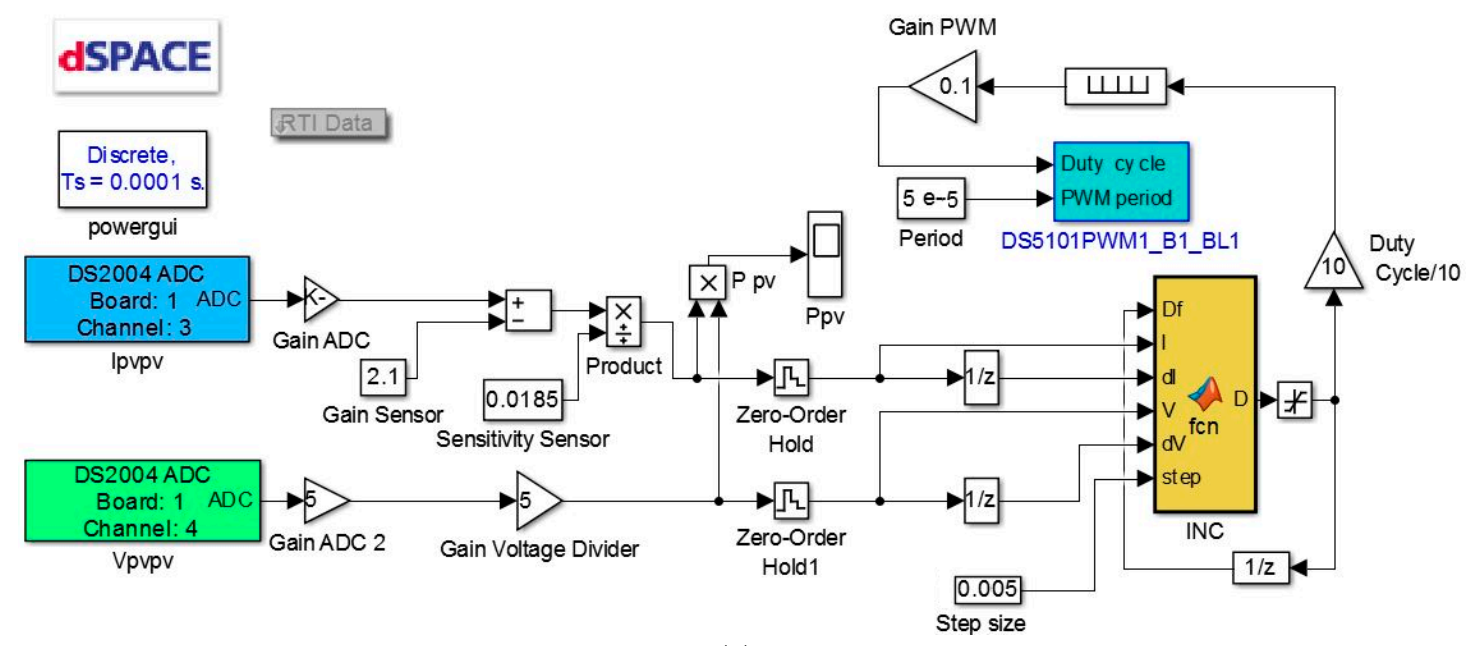

(a)

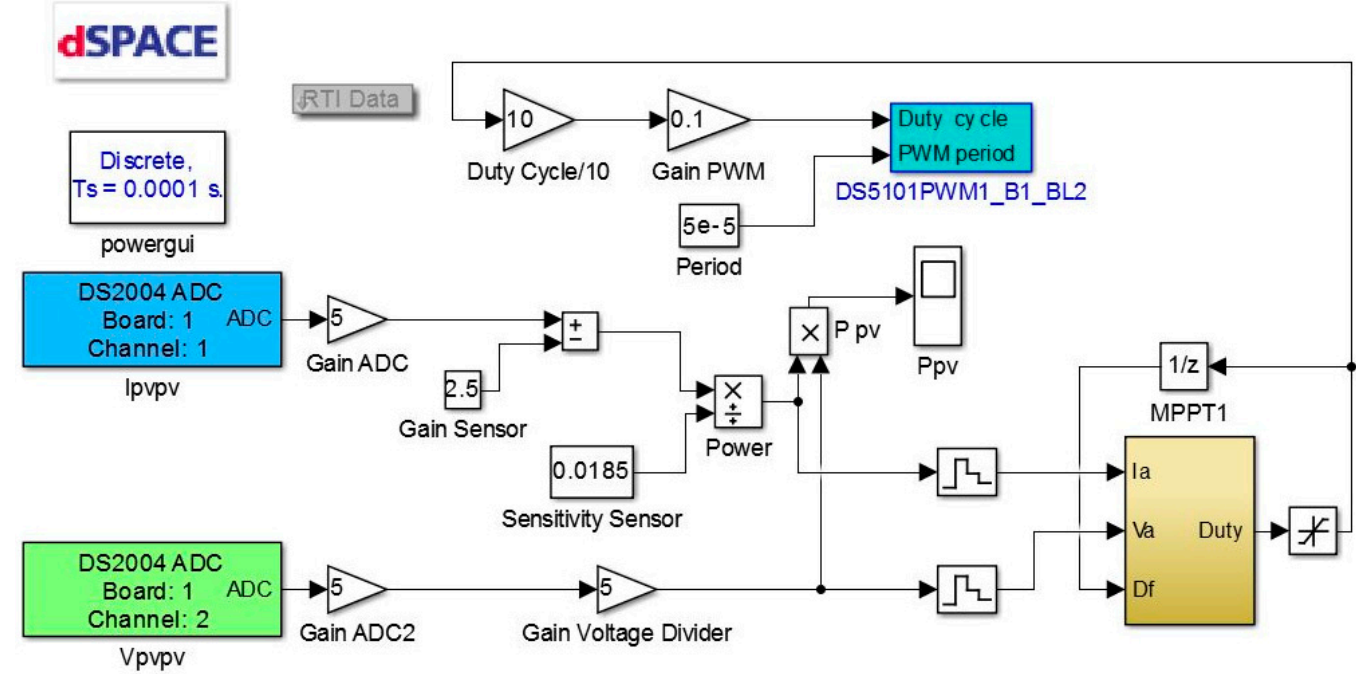

(b)

Figure 6. Real time implementation of (a) IC and (b) P\&O MPPT methods in dSPACE. 
Lookup tables were used to interpolate previously estimated switching energy loss profiles during switching operation. Real time power loss profiles were monitored by multiplication of these losses with the switching frequency. Then, total power loss was calculated over one switching period, in each step time as a function of collector current, $I_{c e}$, collector to emitter voltage $V_{c e}$ and temperature by addition of switching and conduction losses.

Total power losses were then used as input to heat source within thermal model, as shown in Figure 7a. Thermal resistance $R_{t h}$ and capacitance $C_{t h}$ for each individual of Foster equivalent thermal network, as shown in Figure $7 \mathrm{~b}$, were extracted by curve fitting using least square method. The equivalence of foster thermal [28] network is defined in Equation (17) as:

$$
T_{m}(s)=\sum_{n=1}^{N} \frac{1 / \mathrm{Cth}_{n}}{s+1 / \tau_{n}} P_{n}(s)
$$

where $P$ is the heat source. Temperature, $T_{j}$, of each layer was represented for heating source. By applying forward rectangular Euler's rule, thermal equation in $z$-domain is [28]:

$$
\Delta T=\frac{P_{i}}{C_{t h}} \frac{1}{z-1}-\frac{\Delta T}{R_{t h} C_{t h}} \frac{1}{z-1}
$$

Using Simulink blocks, mathematical equivalent model was implemented in thermal block. Estimated temperature is then fed back into power loss model for continuous monitoring [29].

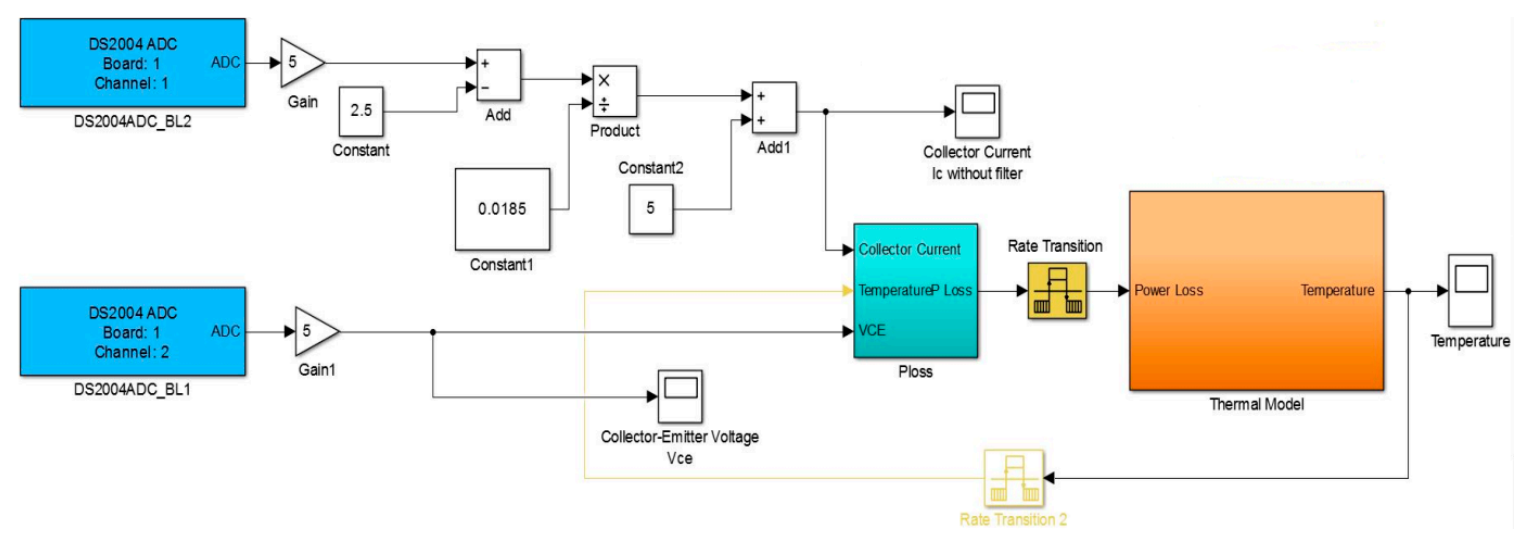

(a)

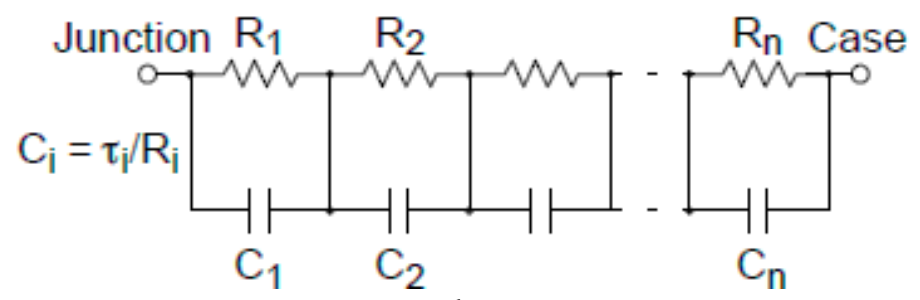

(b)

Figure 7. (a) Real time implementation of electro thermal model in dSPACE; and (b) foster thermal network. 


\section{Electro Thermal Performance of Photovoltaic Solar System under Incremental Conductance and Perturb and Observe Algorithms}

\subsection{Simulated and Experimental Characteristics of Photovoltai Module}

PV module performance was examined under different irradiation levels experimentally and compared with numerical simulation results. $I-V$ and $P-V$ characteristics under different irradiation levels are shown in Figure 8a,b while different load characteristics were applied experimentally along with simulation which results at $22{ }^{\circ} \mathrm{C}$ ambient temperature. Differences between the simulated and experimental results are due to the heat and cable losses which are neglected in the computed analysis.

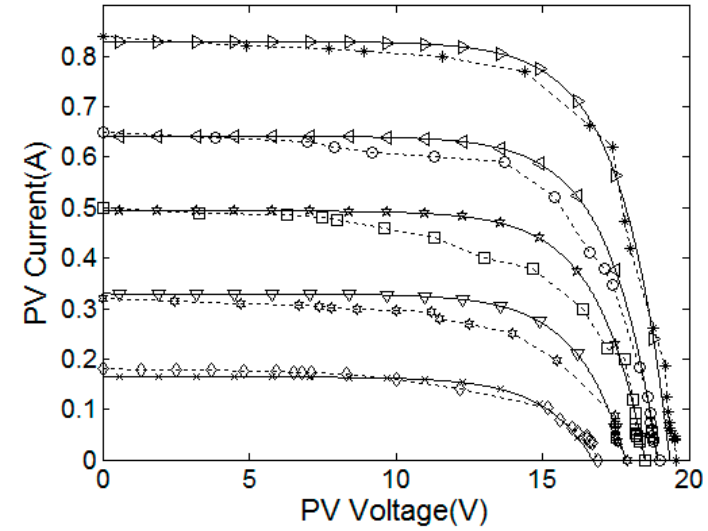

(a)

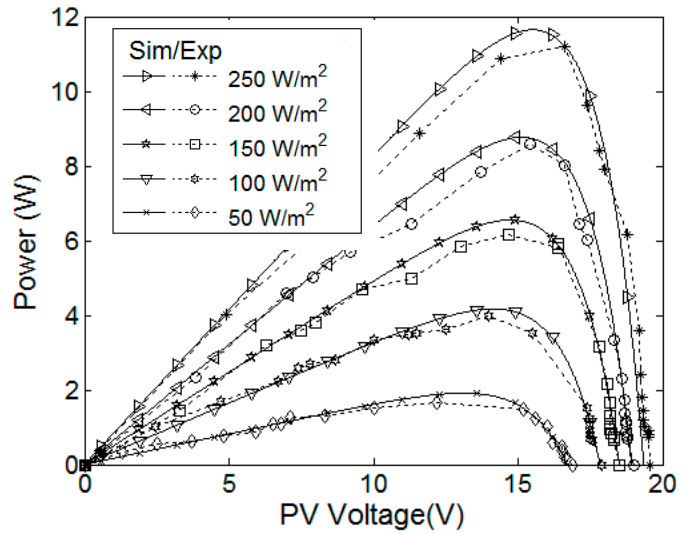

(b)

Figure 8. Experimental (a) $I-V$ and (b) $P-V$ characteristics at different irradiances of halogen bulb.

In order to assess an accurate temperature monitoring with thermal camera, no heat sink was attached to switching device. Light controlled chamber, with ten portions, was used to vary irradiance. By this way, any thermal runaway on PECs was avoided due to the increased current characteristics at higher irradiance.

As irradiance level decreases, MPPT voltage changes more drastically compared to higher irradiance level. Hence, wider ranges of duty cycle operating points were examined for verifying thermal stress difference between $\mathrm{P} \& \mathrm{O}$ and IC algorithms. IGBT was initially operated in continuous conduction mode with a constant gate voltage of $15 \mathrm{~V}$ for thermal model parameter estimation. Temperature was monitored by thermal imaging and recorded each $5 \mathrm{~s}$. Based on the obtained transient temperature profile, thermal impedance for each component has been interpolated using Equation (17) and it is shown in Table 3.

Table 3. Thermal impedance characteristics of IGBT.

\begin{tabular}{ccccccc}
\hline \multirow{2}{*}{ Device LUT } & \multicolumn{3}{c}{ Thermal Capacitance } & \multicolumn{3}{c}{ Thermal Resistance } \\
\cline { 2 - 7 } & $\boldsymbol{C}_{\mathrm{th}, \mathbf{1}}$ & $\boldsymbol{C}_{\mathrm{th}, \mathbf{2}}$ & $\boldsymbol{C}_{\mathrm{th}, \mathbf{3}}$ & $\boldsymbol{R}_{\mathrm{th}, \mathbf{1}}$ & $\boldsymbol{R}_{\mathrm{th}, \mathbf{2}}$ & $\boldsymbol{R}_{\mathrm{th}, \mathbf{3}}$ \\
\hline IGBT & 0.134 & 0.294 & 26.89 & 0.343 & 0.329 & 0.322 \\
\hline
\end{tabular}

\subsection{Thermal Comparison of Incremental Conductance and Perturb and Observe Maximum Power Point Tracking Algorithms}

Thermal performance of IC and $\mathrm{P} \& \mathrm{O}$ methods was tested under the same environmental conditions. Experimental and simulated PV voltages, current and tracked maximum power as well as the length of the duty cycle by means of percentage are shown in Figure 9a,b, respectively, for the IC algorithm based MPPT. 

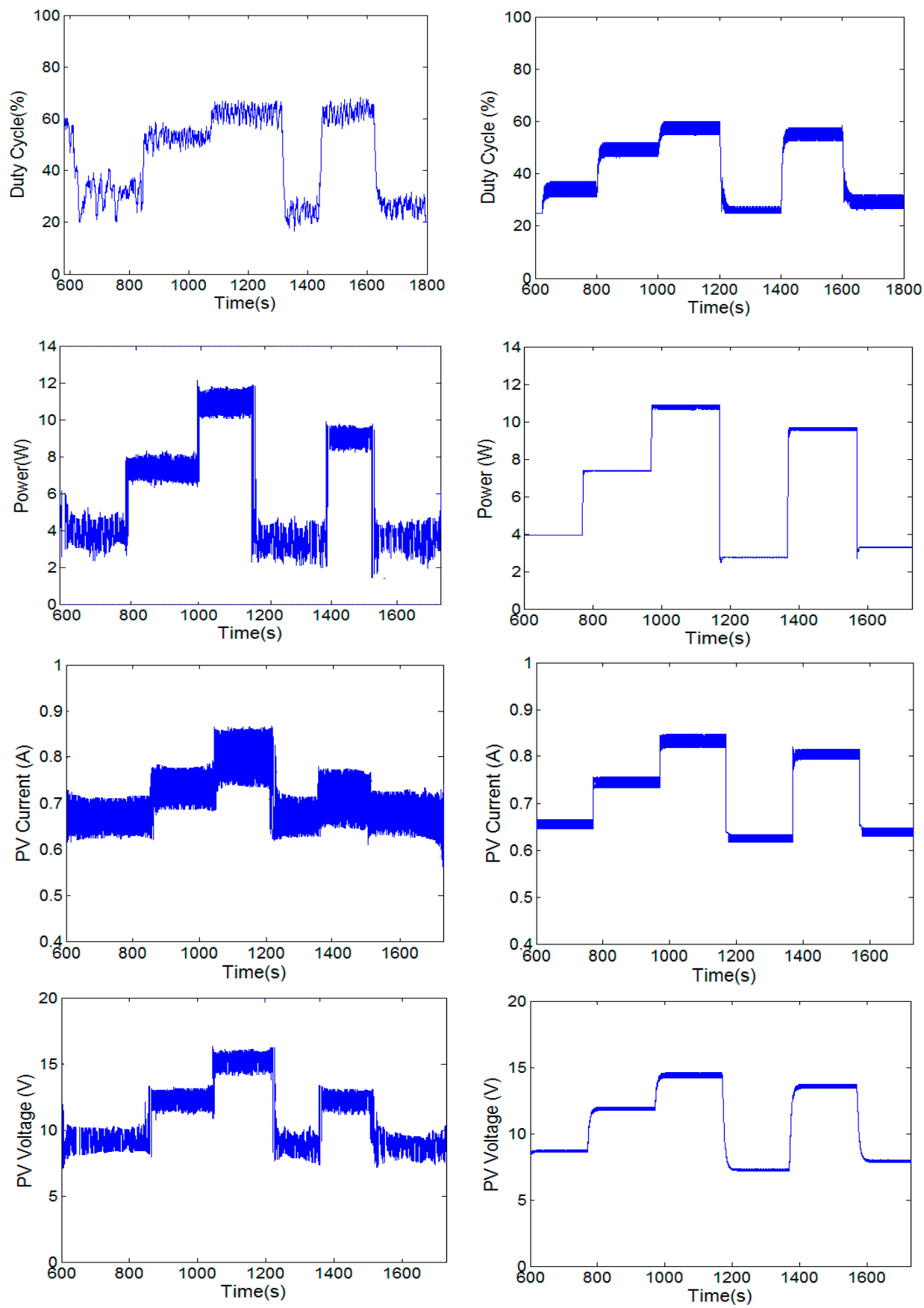

(a)

(b)

Figure 9. (a) Experimental and (b) simulated MPPT duty cycle, power, current voltage with IC.

The analysis can be seen in Figure 10 when the P\&O MPPT method was used. Duty cycle changes during operation in IC algorithm are more drastic compared to the $\mathrm{P} \& \mathrm{O}$ algorithm as it can be illustrated in Figures 9 and 10. The gradual change of duty cycle in $\mathrm{P} \& \mathrm{O}$ algorithm was also reflected on the extracted PV current characteristic due to its slower dynamic working principle. Although, the current it is less oscillatory during each cycle compared to the IC method but this would result in decreased tracking efficiency. In general, both methods show inaccuracies at low irradiances where $\mathrm{P} \& \mathrm{O}$ provided slower response to irradiance changes during all practical and experimental analysis. Power loss profiles of semiconductor switching devices are highly depended on the current signal characteristic, i.e., amplitude, frequency, etc. [30-32]. This was monitored on dSPACE Control Desk for both MPPT methods as illustrated in Figure 11a. It can be clearly seen that there is higher power 
loss profile especially when higher illuminations between 1000 and 1200 and 1400 and $1600 \mathrm{~s}$ are experienced for the IC method. The overall power losses are approximately $10 \mathrm{~W}$ less with the $\mathrm{P} \& \mathrm{O}$ compared to IC method, at the highest possible irradiance level. Switching energy losses for a fraction of analysis time are depicted in Figure 11b. The sharp change of PV current caused by tracking method which is the result of irradiance change, produced more switching losses when IC algorithm is selected. Approximately, one and half times higher power loss can be noticed during turn on-time losses where the device is exposed the highest voltage/current change. Yet, turn off-time losses were very similar in both methods.
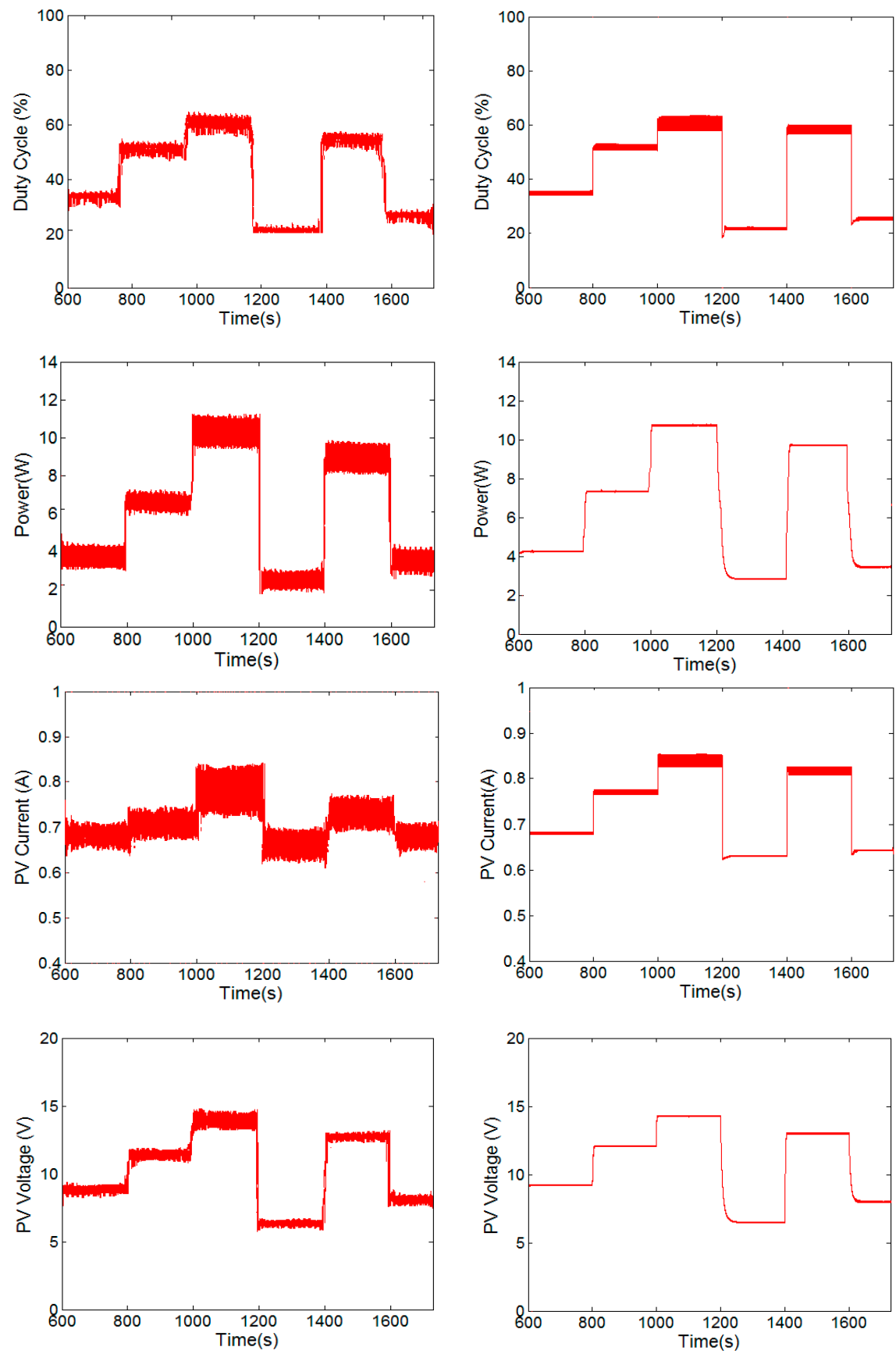

(a)

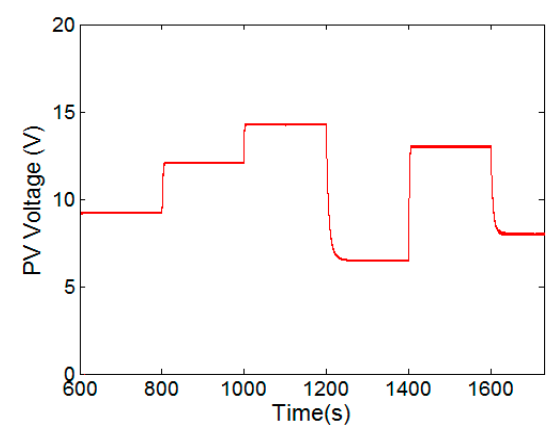

(b)

Figure 10. (a) Experimental and (b) simulated MPPT duty cycle, power, current voltage with P\&O. 


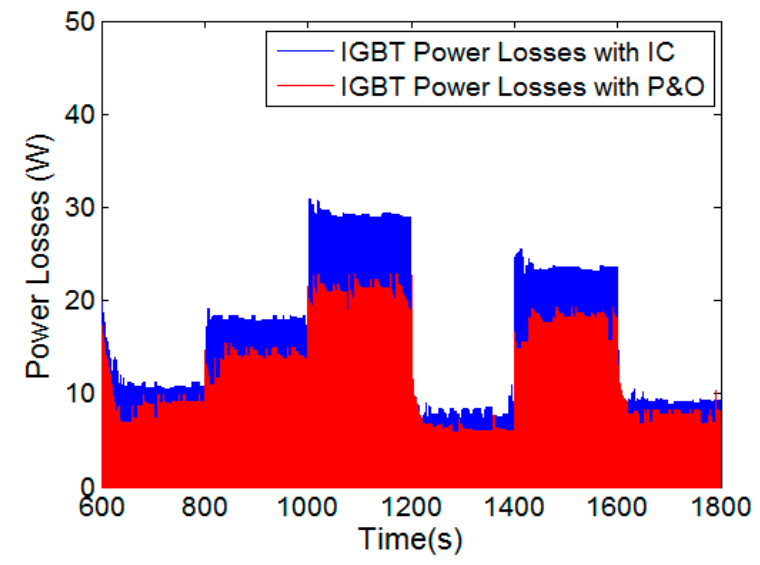

(a)

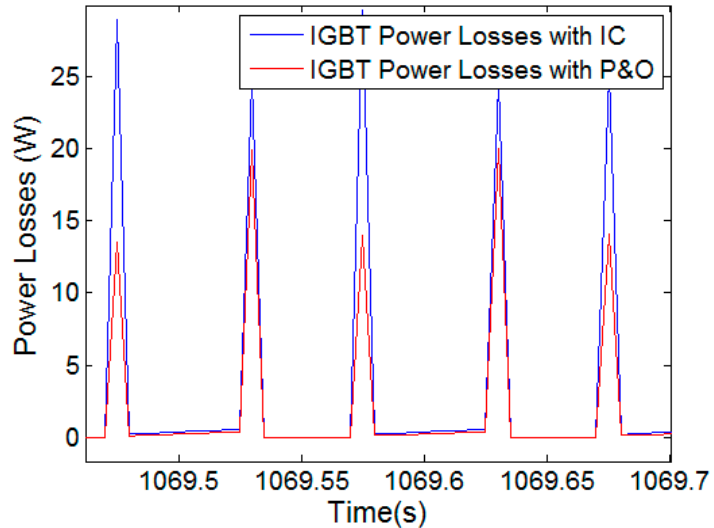

(b)

Figure 11. (a) Total power loss and (b) switching losses comparison when IC and P\&O selected.

Temperature of the PEC was monitored by FLIR T440 thermal camera with frame rate $60 \mathrm{~Hz}$ and a thermal resolution of 76,800 pixels [33]. Tests were performed under $22{ }^{\circ} \mathrm{C}$ ambient temperature. Thermal impedance values in thermal model were also verified by this method. Thermal camera captures, for temperature difference observation when $\mathrm{P} \& \mathrm{O}$ and IC methods were used under $150 \mathrm{~W} / \mathrm{m}^{2}$ and $250 \mathrm{~W} / \mathrm{m}^{2}$, are shown Figures 12 and 13, respectively.

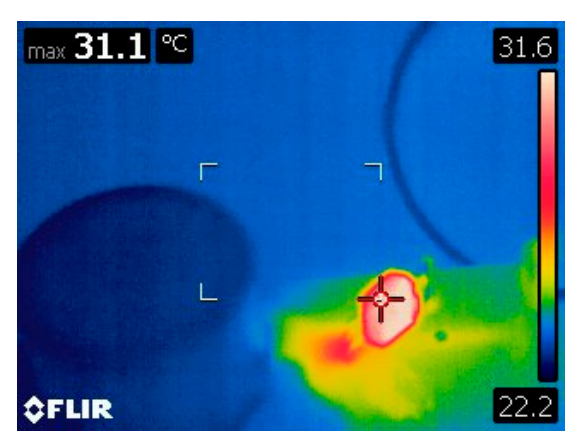

(a)

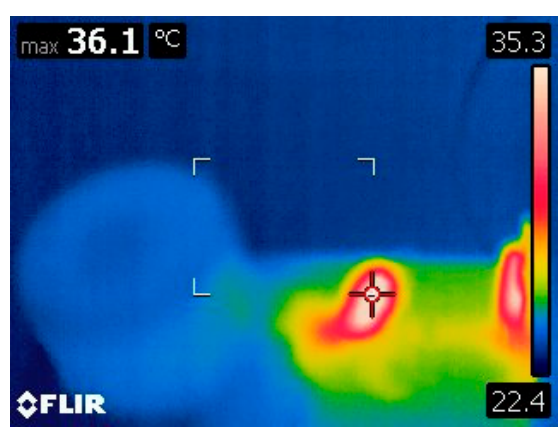

(b)

Figure 12. Thermal camera view of IGBT with $150 \mathrm{~W} / \mathrm{m}^{2}$ when (a) $\mathrm{P} \& \mathrm{O}$ and (b) IC are used.

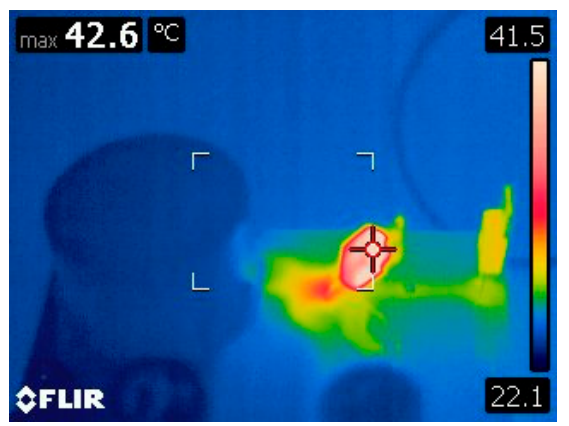

(a)

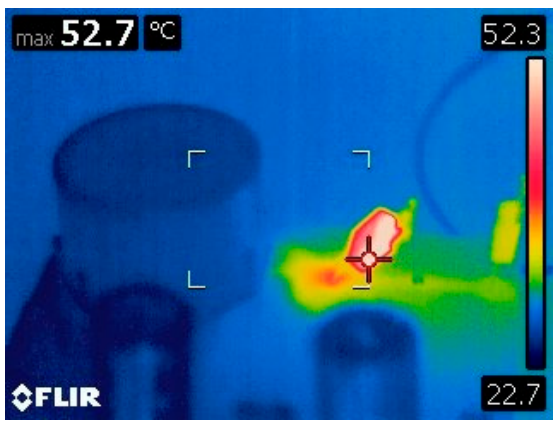

(b)

Figure 13. Thermal images at $250 \mathrm{~W} / \mathrm{m}^{2}$ when (a) $\mathrm{P} \& \mathrm{O}$ and (b) IC are used.

Operating temperature of IGBT is the highest compared to other components' located on PEC. Nevertheless, the IGBT experienced approximately $10^{\circ} \mathrm{C}$ higher temperature when the IC method is selected with $52.7^{\circ} \mathrm{C}$ compared to $42.6^{\circ} \mathrm{C}$ with $\mathrm{P} \& \mathrm{O}$ highest irradiance level, as shown in Figure 13 . Therefore, higher power loss profile caused by IC method affected the operating temperature of the 
IGBT, proportionally. Transient experimental temperature characteristic of the IGBT can be seen in Figure 14a which was observed through in dSPACE Real Time Control Desk where Figure 14b shows the simulated results in Simulink. Steady state temperatures of IGBT captured by thermal camera for each applied irradiance can also be illustrated in Figure 15.

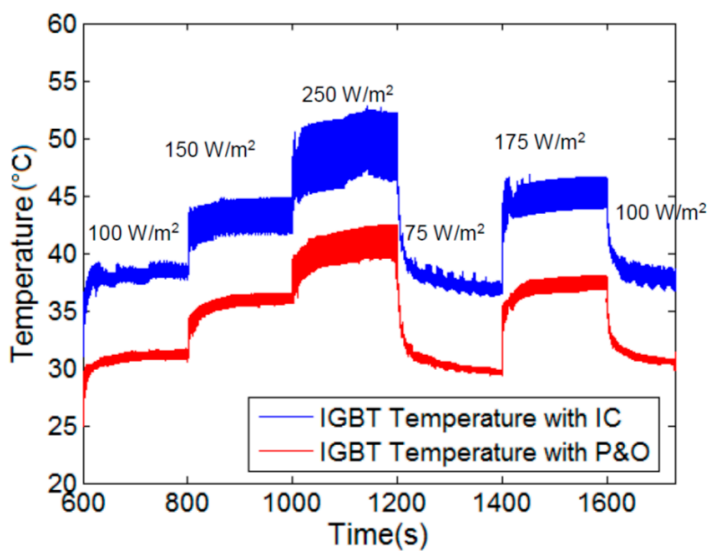

(a)

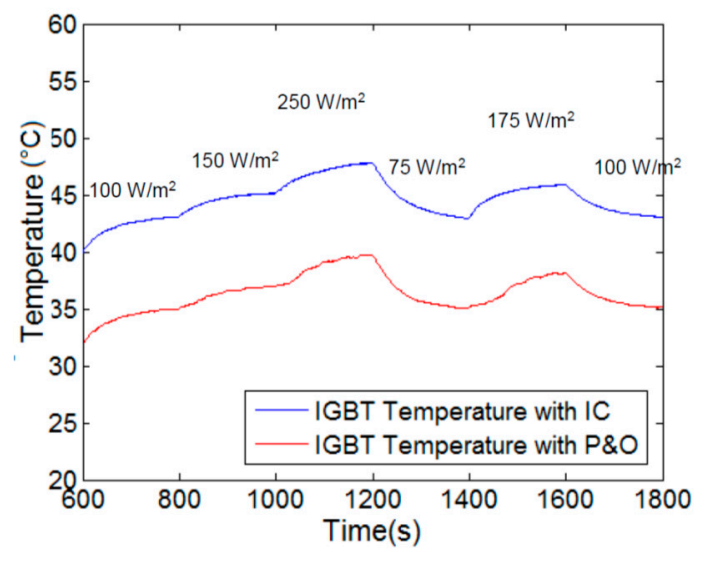

(b)

Figure 14. (a) Transient IGBT temperature in dSPACE; (b) Simulated temperature in Simulink.

IGBT Temperature Variations

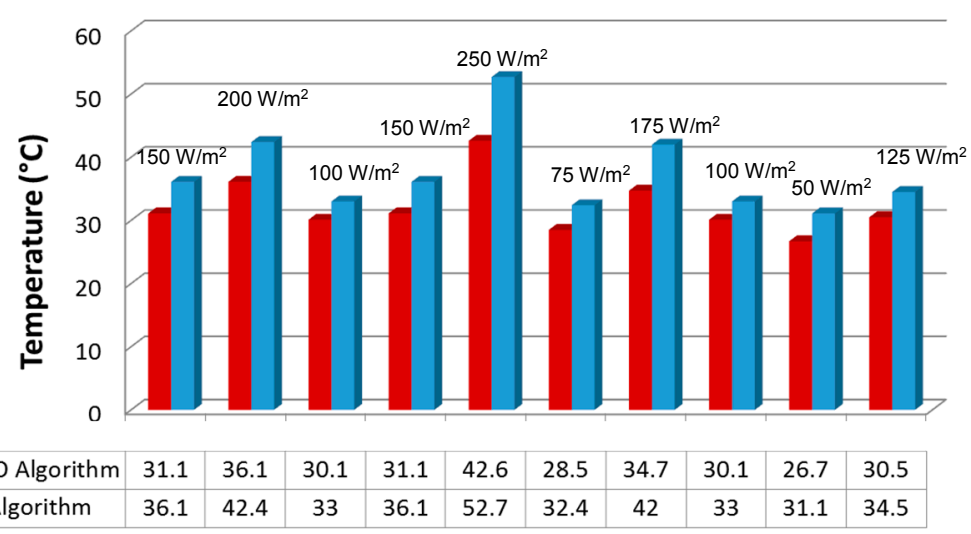

Figure 15. Steady state IGBT temperature comparisons when IC and P\&O used as MPPT methods.

As it can be depicted, a very good approximation was obtained at specified irradiance levels on the PV module with the modelling method. Meanwhile, the IGBT temperature amplitude difference between $\mathrm{P} \& \mathrm{O}$ and IC methods inclines as the irradiance; hence, the MPP increases. Approximately $6{ }^{\circ} \mathrm{C}$ temperature cycling is observed at the $250 \mathrm{~W} / \mathrm{m}^{2}$ when IC was used with up and down boundaries of $52{ }^{\circ} \mathrm{C}$ and $46^{\circ} \mathrm{C}$, respectively. Yet, with the $\mathrm{P} \& \mathrm{O}$ based system, the fluctuations are as low as $4{ }^{\circ} \mathrm{C}$ from $42{ }^{\circ} \mathrm{C}$ to $38^{\circ} \mathrm{C}$, although temperature amplitude changes more drastically along with irradiance variations. The MPPT efficiency comparison between IC and P\&O methods can be seen in Figure 16. At lower irradiance levels, both methods showed poor performance. Overall, the IC method offers more stable tracking efficiency under changing irradiance conditions and provides an average of 97.59\% efficiency compared to the average efficiency of P\&O method which was calculated as 94.25\%. 


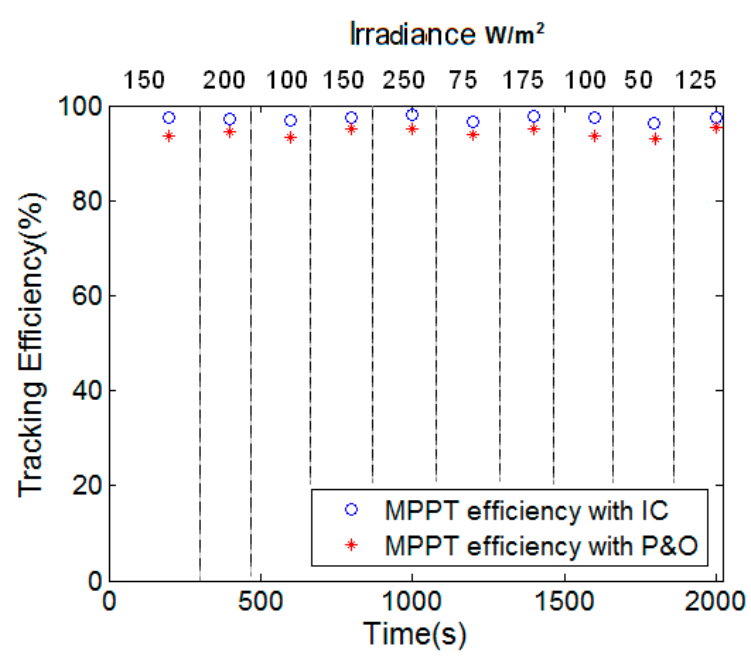

Figure 16. MPPT efficiency comparison.

\section{Lifetime Comparison Analysis}

Lifetime analysis for power electronic devices can be evaluated by using Weibull statistics [34]. Devices under test are examined for determining the number of cycles to failure [35]. Reliability of the PECs mostly depends on the associated switching elements (IGBTs), since they are the most easily damaged components [36]. The failure occurs due to the thermo-mechanical stress caused by different thermal expansion characteristics of materials among the IGBT package during temperature changes. The failure mechanisms of these devices are related to the cycling load of the module. Therefore, temperature profile of the IGBT was considered for estimating power cycling lifetime in terms of mean and cycling temperature. A schematic of the lifetime consumption study is shown in Figure 17.

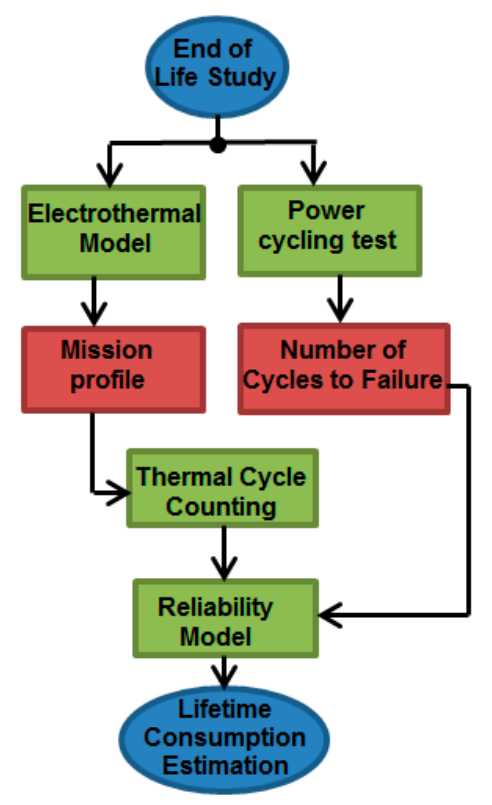

Figure 17. Schematic of a lifetime consumption study.

Initially, number of cycles to failure was obtained by an accelerated power cycling test. Then a temperature load history is collected; a cycle-counting algorithm is then performed to calculate number of thermal cycle across accumulation time and the cumulative number of thermal cycles are summed and compared with referenced thermal cycle to failure to lifetime. The implemented test 
circuit for reliability tests can be seen in Figure 18. The gate signal duration was provided through dSPACE to turn on and off the device. Load current was conducted through power supply unit for generating temperature swing.

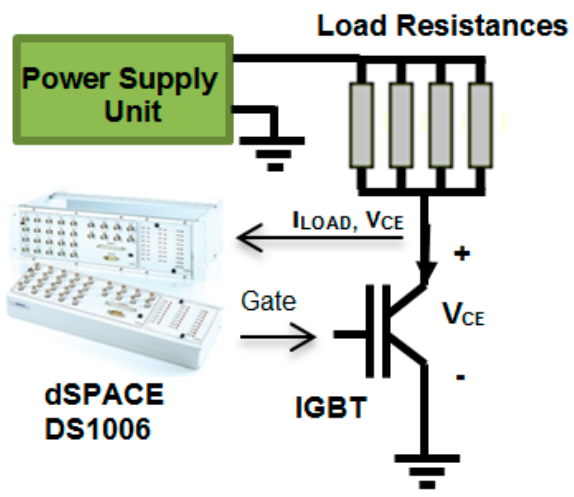

Figure 18. Accelerated life consumption test set-up.

Modelled and measured temperatures are shown in Figure 19a with respect to device current. A total of four different test conditions were applied for the failure test. Model-based data is shown in Figure $19 \mathrm{~b}$ when the temperature swing $(\Delta T)$ was adjusted as $90{ }^{\circ} \mathrm{C}$ and $40{ }^{\circ} \mathrm{C}$ with average temperatures $\left(T_{\mathrm{m}}\right)$ of $80^{\circ} \mathrm{C}$ and $60^{\circ} \mathrm{C}$, respectively.

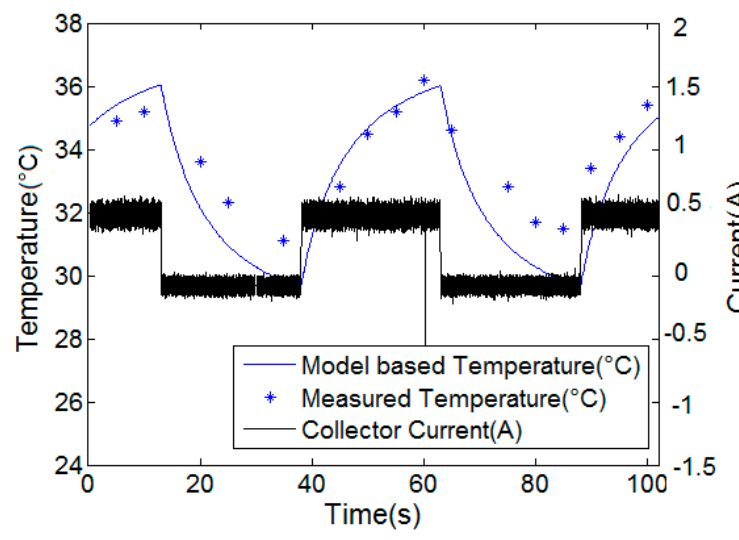

(a)

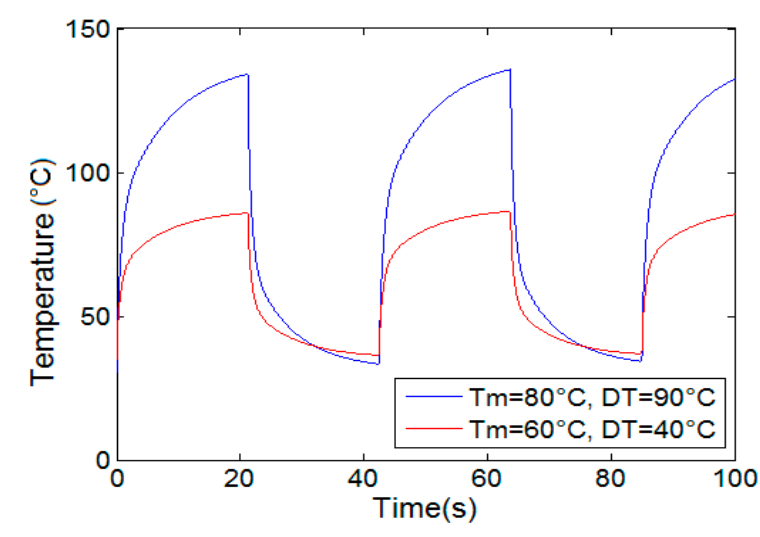

(b)

Figure 19. (a) Temperature monitoring by thermal camera (b) Accelerated power cycling test data.

The thermal resistance increment is commonly due to the solder fatigue and the on-state voltage increment is caused by the wire bond lift off [37]. Hence, device temperature and the forward voltage of the IGBT were monitored during the test, as shown in Figure 20. The mean temperature was $60{ }^{\circ} \mathrm{C}$ and temperature variation was $90^{\circ} \mathrm{C}$. Failure criteria were defined as $25 \%$ increase of the temperature. Voltage across the device was no longer constant after 190,000 cycles and more than 30\% increase was detected in the device temperature after 225,000 cycles. This was considered as indication of failure. 


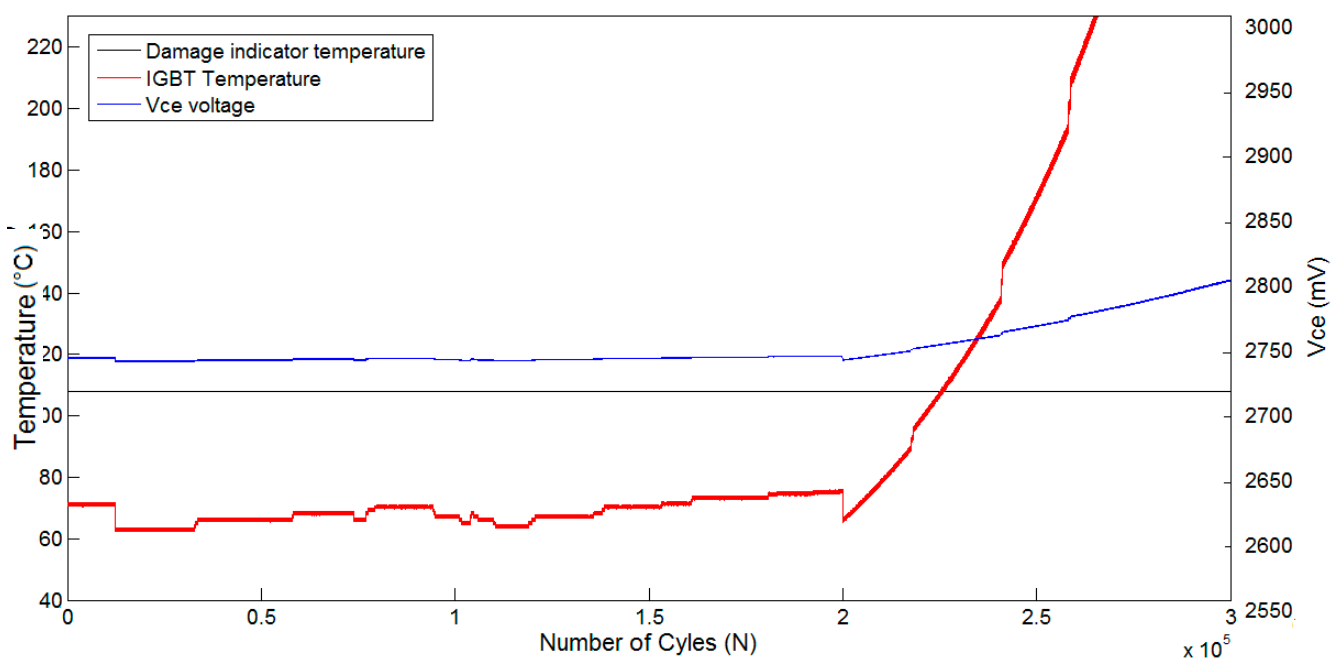

Figure 20. Power cycling test results.

A modified Coffin-Manson-Arrhenius lifetime model [37] was used to define cycle to failure data as a function of mean temperature, $T_{m}$ and temperature variation, $\Delta T$ as expressed in Equation (19):

$$
N_{f}=A\left(\Delta T_{j}\right)^{\alpha} \cdot e^{\left(\frac{E_{a}}{k_{b} \cdot T_{m}}\right)}
$$

where $N_{f}$ is expected number of cycles to failure, $k_{b}$ is Boltzman constant, $1.38 \times 10^{-23} \mathrm{~J} \cdot \mathrm{K}^{-1}, E_{a}$ is the activation energy, $1.3 \times 10^{-19} \mathrm{~J}, A$ and $\alpha$ are the constants, 610 and -5 , respectively, which are fitted by the least squares method. The lifetime curves as a function of temperature variation with respect to number of cycles to failure are presented in Figure 21.

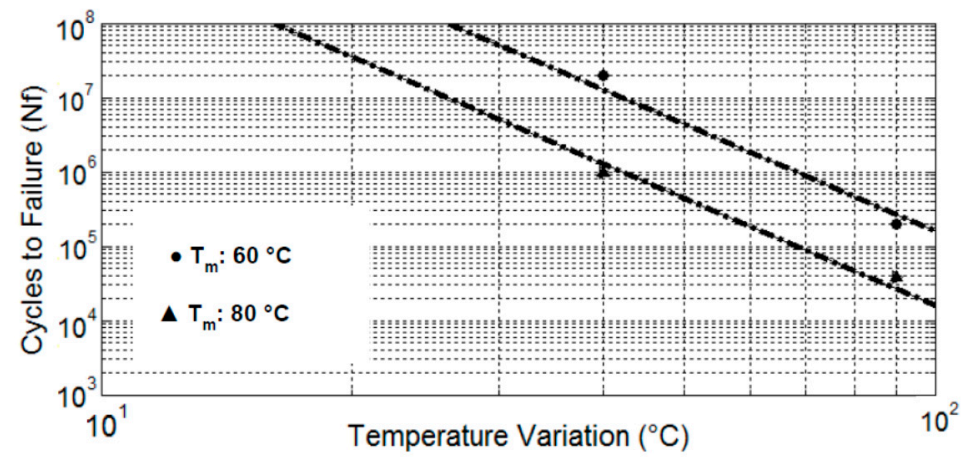

Figure 21. Lifetime curves.

For lifetime estimation analysis purpose, the Rainflow counting algorithm tool [38] was used to evaluate the temperature variation profile for the IGBT when P\&O and IC MPPT algorithms were applied to the PV system. The counted numbers of cycles for both temperature profiles are shown in Figure 22a,b. The majority of thermal variations $(\Delta T)$ are estimated at low values for both algorithms and the mean temperature changes $\left(T_{\mathrm{m}}\right)$ between $40-55^{\circ} \mathrm{C}$ for IC and $35-45^{\circ} \mathrm{C}$ for $\mathrm{P} \& \mathrm{O}$. The highest number of cycles for IC is approximately 2000 at $43^{\circ} \mathrm{C}$ where it is 2500 cycles for the $\mathrm{P} \& \mathrm{O}$ algorithm at $35^{\circ} \mathrm{C}$. 


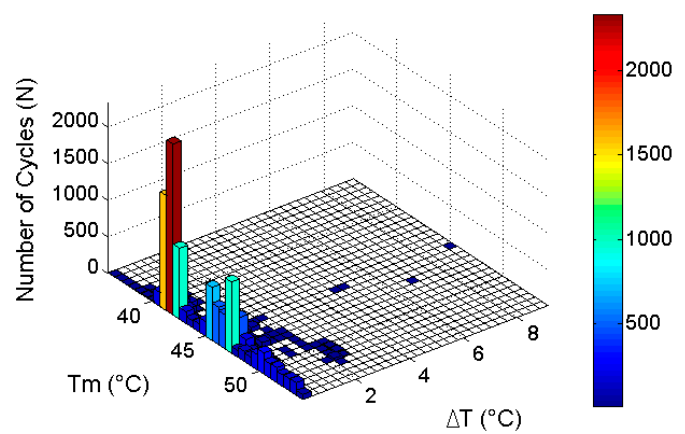

(a)

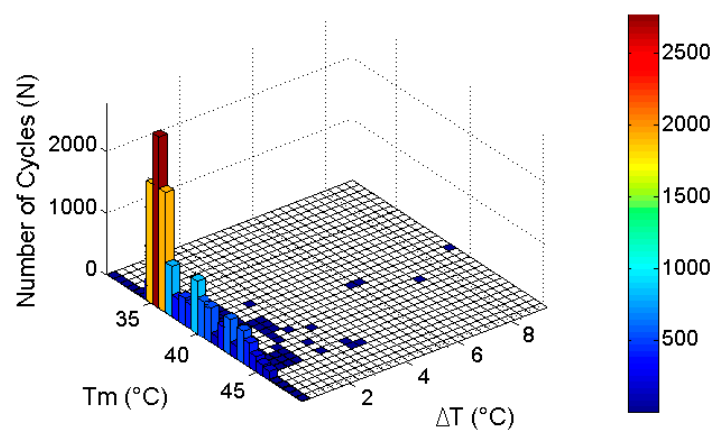

(b)

Figure 22. Number of cycles found with (a) IC and (b) P\&O algorithms.

In order to achieve total life consumption (TLC) caused by the combined effect load profile, the Palmgren-Miner linear damage accumulation rule [37] was applied and modelled for failure prediction. It can be expressed as in Equation (20):

$$
T L C=\sum_{i=1}^{j} \frac{n_{i}}{N_{i}}
$$

where $n_{i}$ is the number of cycles, $N_{i}$ is the measured lifetime in the $i_{\text {th }}$ profile and $j$ is the total number of load profile. The rule states that failure happens when condition TLC $=1$ occurs. Numbers of life consumption of IGBT for IC and P\&O algorithms are shown in Figure 23a,b. The TLC was calculated by addition of each consumption data by using Equation (20). As it can be observed, less amount of high temperature variation, i.e., at $10^{\circ} \mathrm{C}$ mean temperature of $43{ }^{\circ} \mathrm{C}$ for $\mathrm{IC}$ and $35^{\circ} \mathrm{C}$ for $\mathrm{P} \& \mathrm{O}$ methods cause approximately the same amount of life consumption with ten times higher number of cycles at low temperature variation (i.e., $0.5{ }^{\circ} \mathrm{C}$ ) at $5{ }^{\circ} \mathrm{C}$ higher mean temperatures. TLC for IGBT, used in boost converter, was found as $4.817 \times 10^{-5}$ while this was $3.44 \times 10^{-5}$ for $\mathrm{P} \& \mathrm{O}$ algorithm. Thus, approximately 1.4 times higher TLC was observed for the IC MPPT method usage under the same loading and environmental conditions compared to the $\mathrm{P} \& \mathrm{O}$ algorithm for the described PV system.

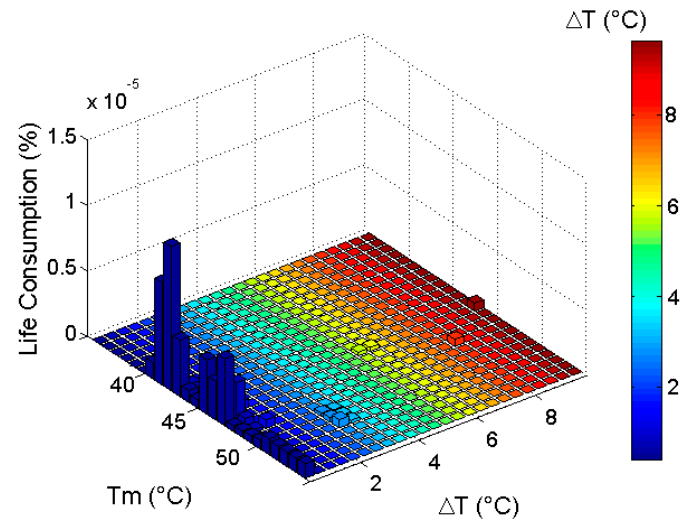

(a)

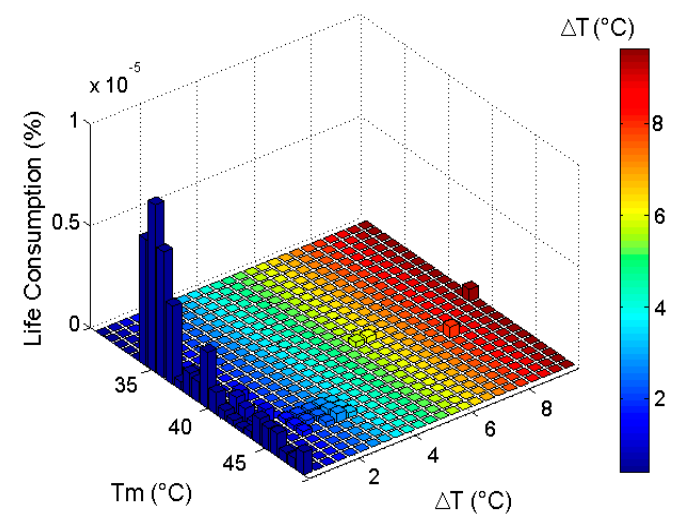

(b)

Figure 23. Lifetime Consumption with (a) IC and (b) P\&O algorithms.

\section{Discussion}

\subsection{Dynamics of the Perturb and Observe and Incremental Conductance Maximum Power Point Tracking Algorithms}

Prior to discussing the reasons behind the different temperature profiles of the switching device of the converters while operated by P\&O and IC MPPT algorithms, it is worth recalling their operating principles and main causes of the electro-thermal power loss occurring which affects the reliability [39]. 
The $\mathrm{P} \& \mathrm{O}$ algorithm simply introduces perturbations in the duty cycle of the power converter which leads to changes in the PV voltage and current. Subsequently, by observing the change in the operating power, the duty cycle is further increased or decreased by the amount of the perturbation step size as the direction of the perturbation is retained. It should be noted that, once the maximum power point is reached, the conventional $\mathrm{P} \& \mathrm{O}$ algorithm begins to oscillate around it by a certain amount, depending on this perturbation step size.

The IC, on the other hand, incrementally compares the ratio of the derivative of the conductance with the instantaneous conductance by using Equations (6)-(10) and updates the duty cycle, accordingly. Similar to the $\mathrm{P} \& \mathrm{O}$, the maximum power point where the condition of $\mathrm{d} I / \mathrm{d} V+I / V=0$ is difficult to be operated; hence the PWM signal oscillates around this point.

Although in theory, both methods provide very close tracking efficiencies as discussed in the literature, the working principle of the $\mathrm{P} \& \mathrm{O}$ consists of a hill climbing nature which has slower dynamics compared to the IC algorithm's incremental ratio working principle. This is the one main reason for the difference in the average values of the tracking efficiencies between both algorithms where the INC performs $3 \%$ better for the applied test conditions compared to the $\mathrm{P} \& \mathrm{O}$. The selected perturbation step time, which is 0.005 , has also a significant effect on the efficiency and oscillations during varying irradiance conditions. A further optimised perturbation step size would increase the efficiency for both methods and vice versa.

\subsection{Efficiency of the Perturb and Observe and Incremental Conductance Maximum Power Point Tracking Algorithms}

The efficiency of the P\&O method is low at the sharp decrements of the irradiance levels such as at 600, 1200 and $1800 \mathrm{~s}$ due to the constant perturbation size. The same method has better efficiency at the higher irradiance levels; however it is not as high as the IC due to its slower dynamics. One other reason is that the perturbation step is not sufficient to follow the rapid increase in the MPP, yet the IC has faster working dynamics and provides better tracking efficiency under minimum and maximum light conditions. It continuously inspects the ratio between derivative and instantaneous conductance to update the duty cycle rather than producing perturbations and updating the duty cycle based on the direction of the slope by using a hill climbing method. The searching direction can get confused with $\mathrm{P} \& \mathrm{O}$ due to experimental noise which results in reduced tracking efficiency as well. On the other hand, at medium irradiances, i.e., $125-175 \mathrm{~W} / \mathrm{m}^{2}$, the efficiency between both algorithms was found similar.

Lower efficiencies at low irradiance conditions, i.e., around $25-75 \mathrm{~W} / \mathrm{m}^{2}$, are due to the constant perturbation step size which causes undesired oscillations on the very low current drawn from the PV panel [14]. The current oscillations result in oscillations in power and the MPP tracking is affected negatively for both P\&O and INC methods. Specifically, the low efficiencies for the IC method at low irradiance conditions are mostly related to the oscillatory behaviour of the duty cycle of the converter which does not allow the voltage and current to settle down smoothly as seen in Figure 9a; hence, the MPP condition cannot be stabilised constantly as mentioned in references [14,15].

\subsection{Impact of the Perturb and Observe and Incremental Conductance Algorithms on the Electro-Thermal Performance of Insulated Gate Bipolar Transistor}

According to the experimental and simulated analysis discussed above, the IC method was found as more efficient compared to the $\mathrm{P} \& \mathrm{O}$ method under identical operating conditions which is in agreement with the previous literature studies. Specifically, the IC yield better efficiency for drastic changes and the $\mathrm{P} \& \mathrm{O}$ method has slower dynamics and offers lower efficiency due to the perturbed PV output parameters (oscillation may cause divergence) in every MPPT cycle, although it is mostly accepted as easier to implement.

Having studied the tracking efficiency, the reflection of the dynamics of both methods on the electro-thermal performance of the switching devices of the converters can be further analysed. To begin with, since the IC method was found as more efficient than the P\&O method, theoretically it 
can deliver more power from the PV panel under identical working environment. This, in turn, results in more current drawn through the converter as experimentally and theoretically shown in Figures 9 and 10. It was initially stated in Equations (14)-(16) through that the current increase causes more power losses for the switching devices and it is also a function of both duty cycle and temperature.

This is the main reason why the IC method has a higher loss profile compared to the P\&O method which causes higher temperature and lifetime consumption. In particular, for instance, at the highest irradiance, the duty cycle is increased by both algorithms to extract the maximum available power where the IC method showed better efficiency. The converter extracted $11.2 \mathrm{~W}$ average power when operated by IC whereas this was $10.5 \mathrm{~W}$ with the P\&O method. The average duty cycle provided by the IC was $63 \%$ where it was only $59 \%$ from the P\&O method. This clearly shows that with the IC method, longer conduction time occurred on the switching device compared to the P\&O method. This leads to more current passing through the device in on-stage; hence, causes higher conduction losses as shown in Figure 11a,b. The increments in the average temperature profile with IC and the fluctuations are related to this analysis as can be depicted in Figure $14 \mathrm{a}, \mathrm{b}$. As a result of the lower temperature profile, the P\&O caused 1.4 times less lifetime consumption on the switching device compared to the IC method.

\subsection{Future Direction}

It is worth noting that the outcomes of this work are based on the conventional IC and P\&O methods under identical operating conditions by using direct duty cycle MPPT without any further controller. Performance utilisation studies in literatures [14,15] such as the adaptive time step adjustments would offer more efficient MPPT; hence the thermal profile of the switching devices would change accordingly. These systems work based on the marginal error tracking method with addition of tuneable controller parameters to increase the tracking speed and to reduce the oscillations. They would require complex and more expensive control circuitry. Also, selecting the correct perturbation step size is important for achieving optimised efficiencies. A further research direction would be the investigation of the utilised MPPT methods and their effects on the lifetime of the switching devices operated in different PV converters.

\section{Conclusions}

Effects of IC and P\&O PMAs on the electro-thermal performance and lifetime of the IGBT used as switching element of PEC were presented. Compared to the P\&O method, thermal cycling on the IGBT component was found to be approximately $4{ }^{\circ} \mathrm{C}$ higher when the IC method is operated and the steady state temperature was $52.7^{\circ} \mathrm{C}$, while this was $42.6^{\circ} \mathrm{C}$ with $\mathrm{P} \& \mathrm{O}$. The lifetime of such a semiconductor component depends on the thermal variation caused by changing operating conditions. This was investigated in this work with experimental power cycling test-based lifetime consumption monitoring. Number of cycles to failure was estimated by this test and number of cycles in temperature profile of IGBT used in PEC was counted by a Rainflow algorithm. Then, lifetime consumption was calculated based on the Palmgren-Miner linear damage accumulation rule. The system operated by the IC method was found to be less reliable compared to the one with $\mathrm{P} \& \mathrm{O}$, when they are operated under the same operating conditions. IC method was found to cause 1.4 more life consumption. Consequently, the IC method is superior in terms of tracking efficiency and response to sudden irradiance changes on PV module based on this study; however, it causes higher varied temperatures on IGBT and reduces its reliability. The results presented in this paper, for the first time in the literature, clearly show that the reliability of the converter switching devices is affected by different MPPT methods in PV applications. An interesting future study needs to be done for further investigating this phenomenon under different operating parameters, i.e., power rating and environmental conditions. As the future trend is to increase the power capacity of solar PV applications, this research states that the lifetime consumption for the converter units will be also affected and life consumption estimation techniques will be required for conscious assessment of the reliability of these devices. Materials with less thermal 
impedance properties, such as silicon carbides, would be desirable for the manufacturing of more reliable devices. Advanced cooling techniques would also be essential for those systems.

Acknowledgments: Authors acknowledge Manchester Metropolitan University and Advanced Industrial Diagnostic Research Centre for the research fund and financial support to carry on this work.

Author Contributions: All authors contributed equally to the research described in this work. Canras Batunlu, Mohamad Alrweq and Alhussein Albarbar conceived and designed the experiments. Canras Batunlu, Mohamad Alrweq and Alhussein Albarbar performed the experiments and analyzed the data, Canras Batunlu contributed modelling and analysis tools; Canras Batunlu and Alhussein Albarbar wrote the paper.

Conflicts of Interest: The authors declare no conflict of interest.

\section{Nomenclature}

$\begin{array}{ll}\text { PMA } & \text { Power Management Algorithms } \\ \text { MPPT } & \text { Maximum Power Point Tracking } \\ \text { PEC } & \text { Power Electronic Converter } \\ \text { P\&O } & \text { Perturb and Observe } \\ \text { IC } & \text { Incremental Conductance } \\ \text { PV } & \text { Photovoltaic } \\ \text { IGBT } & \text { Insulated Gate Bipolar Transistor }\end{array}$

\section{References}

1. Alam, M.K.; Khan, F.; Johnson, J.; Flicker, J. A comprehensive review of catastrophic faults in PV arrays: Types, detection, and mitigation techniques. IEEE J. Photovolt. 2015, 5, 982-997. [CrossRef]

2. DeGraaff, D.; Lacerda, R.; Campeau, Z. Degradation mechanisms in Si module technologies observed in the field; their analysis and statistics. In Proceedings of the NREL 2011 Photovoltaic Module Reliability Workshop, Golden, CO, USA, 16-17 February 2011.

3. Tsoutsos, T.; Tournaki, S.; Gkouskos, Z.; Masson, G.; Holden, J.; Medina, E.R.; Rubio, A.I.H. Certification and Qualification of PV Installers in Europe Training and Certification Methodology. Available online: http: //pvtrin.eu/assets/media/PDF/Publications/published_articles/262.\%20TUC_EPIA_D6.12.pdf (accessed on 27 October 2016).

4. Moore, L.M.; Post, H.N. Five years of operating experience at a large, utility-scale photovoltaic generating plant. Prog. Photovolt. Res. Appl. 2008, 16, 249-259. [CrossRef]

5. Wang, H.; Ma, K.; Blaabjerg, F. Design for reliability of power electronic systems. In Proceedings of the IECON 2012-38th Annual Conference on IEEE Industrial Electronics Society, Montreal, QC, Canada, 25-28 October 2012; pp. 33-44.

6. Elgendy, M.A.; Zahawi, B.; Atkinson, D.J. Assessment of perturb and observe MPPT algorithm implementation techniques for PV pumping applications. IEEE Trans. Sustain. Energy 2012, 3, 21-33. [CrossRef]

7. Kish, G.J.; Lee, J.J.; Lehn, P.W. Modelling and control of photovoltaic panels utilising the incremental conductance method for maximum power point tracking. IET Renew. Power Gener. 2012, 6, 259-266. [CrossRef]

8. Zhang, F.; Maddy, J.; Premier, G.; Guwy, A. Novel current sensing photovoltaic maximum power point tracking based on sliding mode control strategy. Sol. Energy 2015, 118, 80-86. [CrossRef]

9. Liu, Y.; Li, M.; Ji, X.; Luo, X.; Wang, M.; Zhang, Y. A comparative study of the maximum power point tracking methods for PV systems. Energy Convers. Manag. 2014, 85, 809-816. [CrossRef]

10. Houssamo, I.; Locment, F.; Sechilariu, M. Maximum power tracking for photovoltaic power system: Development and experimental comparison of two algorithms. Renew. Energy 2010, 35, 2381-2387. [CrossRef]

11. De Brito, M.A.G.; Sampaio, L.P.; Luigi, G.; e Melo, G.A.; Canesin, C.A. Comparative analysis of MPPT techniques for PV applications. In Proceedings of the 2011 International Conference on Clean Electrical Power (ICCEP), Ischia, Italy, 14-16 June 2011. 
12. Banu, I.V.; Beniuga, R.; Istrate, M. Comparative analysis of the perturb-and-observe and incremental conductance MPPT methods. In Proceedings of the 2013 8th International Symposium on Advanced Topics in Electrical Engineering (ATEE), Bucharest, Romania, 23-25 May 2013; pp. 1-4.

13. Azevedo, G.M.S.; Cavalcanti, M.C.; Oliveira, K.C.; Neves, F.A.S.; Lins, Z.D. Comparative evaluation of maximum power point tracking methods for photovoltaic systems. J. Sol. Energy Eng. 2009, 131. [CrossRef]

14. Ishaque, K.; Salam, Z.; Lauss, G. The performance of perturb and observe and incremental conductance maximum power point tracking method under dynamic weather conditions. Appl. Energy 2014, 119, 228-236. [CrossRef]

15. Dash, S.K.; Verma, D.; Nema, S.; Nema, R.K. Comparative analysis of maximum power point (MPP) tracking techniques for solar PV application using MATLAB simulink. In Proceedings of the 2014 Recent Advances and Innovations in Engineering (ICRAIE), Jaipur, India, 9-11 May 2014; pp. 1-7.

16. Mahdi, A.; Tang, W.; Wu, H.; Mahdi, A. Improvement of a MPPT algorithm for PV systems and its experimental validation. In Proceedings of the 10th International Conference on Renewable Energies and Power Quality, Granada, Spain, 23-25 March 2010; pp. 1-6.

17. Mondal, A.; Yuvarajan, S. MPPT scheme for small scale photovoltaic systems using dSPACE. In Proceedings of the 2012 IEEE Green Technologies Conference, Tulsa, OK, USA, 19-20 April 2012; pp. 1-3.

18. Graditi, G.; Adinolfi, G. Energy performances and reliability evaluation of an optimized DMPPT boost converter. In Proceedings of the 2011 International Conference on Clean Electrical Power (ICCEP), Ischia, Italy, 14-16 June 2011; pp. 69-72.

19. Graditi, G.; Adinolfi, G.; Femia, N.; Vitelli, M. Comparative analysis of synchronous rectification boost and diode rectification boost converter for DMPPT applications. In Proceedings of the 2011 IEEE 20th International Symposium On Industrial Electronics (ISIE), Gdansk, Poland, 27-30 June 2011; pp. 1000-1005.

20. Adinolfi, G.; Graditi, G.; Siano, P.; Piccolo, A. Multiobjective optimal design of photovoltaic synchronous boost converters assessing efficiency, reliability, and cost savings. IEEE Trans. Ind. Inform. 2015, 11, 1038-1048. [CrossRef]

21. Rodriguez, C.; Amaratunga, G.A.J. Long-lifetime power inverter for photovoltaic AC modules. IEEE Trans. Ind. Electron. 2008, 55, 2593-2601. [CrossRef]

22. Graditi, G.; Adinolfi, G.; Tina, G.M. Photovoltaic optimizer boost converters: Temperature influence and electro-thermal design. Appl. Energy 2014, 115, 140-150. [CrossRef]

23. Aurilio, G.; Balato, M.; Graditi, G.; Landi, C.; Luiso, M.; Vitelli, M. Fast hybrid MPPT technique for photovoltaic applications: Numerical and experimental validation. Adv. Power Electron. 2014, 2014. [CrossRef]

24. Marinov, A.; Valchev, V. Power loss reduction in electronic inverters trough IGBT-MOSFET combination. Procedia Earth Planet. Sci. 2009, 1, 1539-1543. [CrossRef]

25. Xu, Y.; Chen, H.; Lv, S.; Huang, F.; Hu, Z. Thermal model for power converters based on thermal impedance. J. Power Electron. 2013, 13, 1080-1089. [CrossRef]

26. KC50T-1. Available online: http://www.tieole.com/docs/KC50T-1_Eng_June\%202007.pdf (accessed on 8 October 2016).

27. Yusivar, F.; Farabi, M.Y.; Suryadiningrat, R.; Ananduta, W.W.; Syaifudin, Y. Buck-converter photovoltaic simulator. Int. J. Power Electron. Drive Syst. 2011, 1, 156-167. [CrossRef]

28. Batunlu, C.; Albarbar, A. A technique for mitigating thermal stress and extending life cycle of power electronic converters used for wind turbines. Electronics 2015, 4, 947-968. [CrossRef]

29. Batunlu, C.; Albarbar, A. Real-time system for monitoring the electro-thermal behaviour of power electronic devices used in boost converters. Microelectron. Reliab. 2016, 62, 82-90. [CrossRef]

30. Chen, Q.; Yang, X.; Wang, Z.; Zhang, L.; Zheng, M. Thermal design considerations for integrated power electronics modules based on temperature distribution cases study. In Proceedings of the IEEE Power Electronics Specialists Conference, Orlando, FL, USA, 17-21 June 2007; pp. 1029-1035.

31. Blaabjerg, F.; Ma, K.; Zhou, D. Power electronics and reliability in renewable energy systems. In Proceedings of the 2012 IEEE International Symposium on Industrial Electronics (ISIE), Hangzhou, China, 28-31 May 2012; pp. 19-30.

32. Building-in Reliability into Power Electronics Systems. Available online: http://www.ecpe.org/fileadmin/ user_upload/Public_Relations/Press_Report/ECPE_Workshop_Toulouse_BP_Aug2008.pdf (accessed on 21 October 2016). 
33. NASDAQ:FLIR. FLIR T420 \& T440. 2012. Available online: http://www.flir.com/uploadedFiles/ Thermography_USA/Products/Product_Literature/flir-t420-t440-datasheet.pdf (accessed on 3 July 2016).

34. Zhou, L.; Wu, J.; Sun, P.; Du, X. Junction temperature management of IGBT module in power electronic converters. Microelectron. Reliab. 2014, 54, 2788-2795. [CrossRef]

35. Yang, S.; Bryant, A.; Mawby, P.; Xiang, D.; Ran, L.; Tavner, P. An industry-based survey of reliability in power electronic converters. IEEE Trans. Ind. Appl. 2011, 47, 1441-1451. [CrossRef]

36. Lutz, J.; Schlangenotto, H.; Scheuermann, U.; Doncker, D.R. Semiconductor Power Devices—Physics, Characteristics; Springer: Berlin, Germany, 2011.

37. Suresh, S. Fatigue of Materials; Cambridge University Press: Cambridge, UK, 2012.

38. Nieslony, A. Determination of fragments of multiaxial service loading strongly influencing the fatigue of machine components. Mech. Syst. Signal Process. 2009, 23, 2712-2721. [CrossRef]

39. Batunlu, C.; Albarbar, A. Towards more reliable renewable power systems-thermal performance evaluation of DC/DC boost converters switching devices. Int. J. Power Electr. Drive Syst. 2015, 6, 876-887.

(C) 2016 by the authors; licensee MDPI, Basel, Switzerland. This article is an open access article distributed under the terms and conditions of the Creative Commons Attribution (CC-BY) license (http://creativecommons.org/licenses/by/4.0/). 